\title{
H3K4 trimethylation is required for postnatal pancreatic endocrine cell functional maturation
}

Stephanie A. Campbell ${ }^{1,2}$, Jocelyn Bégin ${ }^{1,2}$, Cassandra L. McDonald ${ }^{1}$, Ben Vanderkruk ${ }^{1,2}$,

Tabea L. Stephan ${ }^{1}$ and Brad G. Hoffman ${ }^{1,2^{*}}$

${ }^{1}$ Department of Surgery, University of British Columbia, Vancouver, BC, V5Z 4E3, Canada

2Diabetes Research Group, British Columbia Children's Hospital Research Institute, 950 West

28th Avenue, Vancouver, BC, V5Z 4H4, Canada

*Corresponding Author/Lead Contact: brad.hoffman@ubc.ca 


\section{Summary}

During pancreas development, endocrine progenitors differentiate into the islet-cell subtypes, which undergo further functional maturation in postnatal islet development. In islet $\beta$ cells, genes involved in glucose-stimulated insulin secretion are activated and glucose exposure increases the insulin response as $\beta$-cells mature. Here, we investigated the role of H3K4 trimethylation in endocrine cell differentiation and functional maturation by disrupting TrxG complex histone methyltransferase activity in mouse endocrine progenitors. In the embryo, genetic inactivation of TrxG component Dpy30 in NEUROG3+ cells did not affect the number of endocrine progenitors or endocrine cell differentiation. H3K4 trimethylation was progressively lost in postnatal islets and the mice displayed elevated random and fasting glycemia, as well as impaired glucose tolerance by postnatal day 24. Although postnatal endocrine cell proportions were equivalent to controls, islet RNA-sequencing revealed a downregulation of genes involved in glucose-stimulated insulin secretion and an upregulation of immature $\beta$-cell genes. Comparison of histone modification enrichment profiles in NEUROG3+ endocrine progenitors and mature islets suggested that genes downregulated by loss of $\mathrm{H} 3 \mathrm{~K} 4$ trimethylation more frequently acquire active histone modifications during maturation. Taken together, these findings suggest that $\mathrm{H} 3 \mathrm{~K} 4$ trimethylation is required for the activation of genes involved in the functional maturation of pancreatic islet endocrine cells.

Keywords: H3K4 trimethylation, TrxG complex, pancreatic islets, functional maturation, diabetes 


\section{Introduction}

Endocrine cell specification from pancreatic progenitors is initiated by the induction of the pro-endocrine factor Neurog3 and subsequent exit from the cell cycle (Jensen et al., 2000; Larsen and Grapin-Botton, 2017; Miyatsuka et al., 2011). NEUROG3 drives expression of downstream transcription factors, such as Neurod1, Nkx2-2, Nkx6-1, Pax6 and Pdx1, which determine further differentiation of endocrine progenitors into hormone-expressing endocrine cells that migrate and coalesce to form proto-islet structures (Bastidas-Ponce et al., 2017; Larsen and Grapin-Botton, 2017). For example, NEUROD1, NKX6-1 and PDX1 drive differentiation of insulin-secreting pancreatic $\beta$-cells (Bastidas-Ponce et al., 2017; Schaffer et al., 2013). In the first few weeks after birth, an increase in endocrine cell proliferation drives islet remodeling into the mature, spherical islet architecture (Bastidas-Ponce et al., 2017; Larsen and Grapin-Botton, 2017). Endocrine cells undergo functional maturation during this postnatal period which involves acquisition of glucose-sensing and hormone-secretion machinery (Bastidas-Ponce et al., 2017; Blum et al., 2012; Larsen and Grapin-Botton, 2017; Liu and Hebrok, 2017). For $\beta$-cell maturation in particular, the transition from immature to mature $\beta$-cells involves activation of the maturity marker Ucn3 (Blum et al., 2012; van der Meulen et al., 2015), metabolic gene expression changes (e.g. switch from high-affinity hexokinase $(H k)$ to low-affinity glucokinase $(G c k))$ and improved glucose-stimulated insulin secretion due to increased glucose exposure (Liu and Hebrok, 2017; Stolovich-Rain et al., 2015). In addition, mature $\beta$-cells are defined by the repression of immature or "disallowed" $\beta$ cell genes that are often detected in stem cell-derived pancreatic $\beta$-like cells and in models of diabetes (Dhawan et al., 2015; Kieffer, 2016; Liu and Hebrok, 2017).

The gene expression changes that occur during endocrine cell differentiation and maturation are associated with specific histone modifications surrounding cis-regulatory loci. In 
addition to histone $\mathrm{H} 3$ lysine 27 acetylation (H3K27ac), genes that become activated during pancreas and endocrine cell differentiation are also associated with histone H3 lysine 4 monomethylation (H3K4me1) at enhancers and $\mathrm{H} 3 \mathrm{~K} 4$ trimethylation ( $\mathrm{H} 3 \mathrm{~K} 4 \mathrm{me} 3)$ at promoters (Heintzman et al., 2009; 2007; Tennant et al., 2013). The majority of H3K4 methylation is catalyzed by the Trithorax Group (TrxG) complexes, which each contain one of six mammalian histone methyltransferases (i.e. SET1A/B, MLL1-4) and a minimum of four core proteins (i.e. ASH2L, DPY30, RBPP5 and WDR5) (Bochyńska et al., 2018; Campbell and Hoffman, 2016; Schuettengruber et al., 2017). Although H3K4 methylation is associated with active chromatin, several studies have suggested that H3K4 methylation is dispensable for gene expression (Dorighi et al., 2017; Hödl and Basler, 2012; Pérez-Lluch et al., 2015; Rickels et al., 2017; Xie et al., 2020).

Previously, we reported that loss of $D p y 30$ and $\mathrm{H} 3 \mathrm{~K} 4$ methylation from PDX ${ }^{+}$progenitors increased the proportion of $\mathrm{CPA}^{+}{ }^{+}$acinar progenitors while $\mathrm{NEUROG}{ }^{+}$endocrine progenitors were reduced, suggesting a role for $\mathrm{H} 3 \mathrm{~K} 4$ methylation in endocrine cell specification (Campbell et al., 2019). While loss of H3K4 trimethylation had a minimal effect on bulk acinar or endocrine cell gene expression, our data suggested a role for $\mathrm{H} 3 \mathrm{~K} 4$ trimethylation in transcriptional maintenance of highly expressed genes in the acinar lineage. However, this model left unresolved whether $\mathrm{H} 3 \mathrm{~K} 4$ trimethylation is required for the transcription of genes essential for islet endocrine cell differentiation or functional maturation. As such, in this study, our objective was to determine the role of $\mathrm{H} 3 \mathrm{~K} 4$ trimethylation in the differentiation and functional maturation of mouse pancreatic endocrine cells. 


\section{Results}

H3K4 trimethylation is lost postnatally in Dpy30 $\Delta \mathrm{N}$ islets

To investigate the role of $\mathrm{H} 3 \mathrm{~K} 4$ trimethylation in endocrine cell differentiation and maturation, we disrupted the TrxG complex core component Dpy30 in NEUROG3 ${ }^{+}$endocrine progenitor cells using Neurog3-Cre driver mice (Schonhoff et al., 2004). DPY30 is required for TrxG catalytic activity or $\mathrm{H} 3 \mathrm{~K} 4$ methylation without affecting complex formation or co-activator activity (Bertero et al., 2015; Haddad et al., 2018). Previously described Dpy30 flox/flox mice (Campbell et al., 2019) were bred to generate experimental Neurog3-Cre; Dpy3 floxflox mice (hereafter known as $D p y 30 \Delta N$ ) and littermate Dpy30 $30^{\text {foxflox }}$ (Cre-negative) control mice. In Dpy30 $\triangle N$ embryos, DPY30 staining was absent from endocrine cells detected with the panendocrine marker chromogranin A (CHGA) beginning at embryonic day 14.5 (E14.5) and at postnatal day 0 (P0), P7, P14 and P24 (Figure 1A). However, DPY30 staining was maintained in the surrounding $D p y 30 \Delta N$ exocrine pancreas, validating deletion of $D p y 30$ in the endocrine lineage. At P24, Cre recombination was highly efficient in $D p y 30 \Delta N$ islets as DPY30 staining was not detected in $95 \%$ of $\mathrm{CHGA}^{+}$endocrine cells (Figure 1B). Co-staining of endocrine cells with $\mathrm{CHGA}$ and $\mathrm{H} 3 \mathrm{~K} 4 \mathrm{me} 3$ revealed a delay between loss of DPY30 protein and H3K4 methylation (Figure 1C). Consistently, $\mathrm{H} 3 \mathrm{~K} 4 \mathrm{me} 3$ staining was absent from $95 \%$ of $\mathrm{CHGA}^{+}$ Dpy30 $\Delta N$ endocrine cells at P24 (Figure 1D). Measuring the median H3K4me3 intensity in $\mathrm{CHGA}^{+}$islets relative to surrounding non-CHGA${ }^{+} \mathrm{H} 3 \mathrm{~K} 4 \mathrm{me} 3$ intensity levels revealed that $\mathrm{H} 3 \mathrm{~K} 4 \mathrm{me} 3$ intensity was maintained in $\mathrm{E} 14.5 \mathrm{CHGA}^{+}$Dpy30 $\Delta \mathrm{N}$ endocrine cells similar to controls (Figure 1E). However, H3K4me3 intensity was progressively decreased from P0 onward and was consistently absent from P14 endocrine cells and thereafter (Figure 1E). At P24, Western blot analysis confirmed that both H3K4me3 ( 4.5-fold, $P<0.01)$ and H3K4me1 $(\sim 2.2$-fold, $P<0.05)$ were significantly reduced in $D p y 30 \Delta \mathrm{N}$ islets (Figure $1 \mathrm{~F}$ ). These data 
suggest that disruption of Dpy30 in NEUROG3+ endocrine progenitors results in loss of DPY30 protein from embryonic endocrine cells and in the delayed loss of H3K4 trimethylation in postnatal islets.

Loss of Dpy30 does not affect NEUROG3+ endocrine progenitor cell specification

To determine whether deletion of Dpy30 in NEUROG3 ${ }^{+}$endocrine progenitors altered the proportion of islet endocrine cells, we first examined the ratio of NEUROG3 ${ }^{+}$endocrine progenitors to $\mathrm{SOX}^{+}$pancreas progenitors and determined there was no significant difference in E14.5 control and Dpy30 $\Delta \mathrm{N}$ pancreas (Figure $2 \mathrm{~A}-\mathrm{B}$ ). Next, co-staining for insulin ${ }^{+} \beta$-cells, glucagon $^{+} \alpha$-cells and somatostatin ${ }^{+} \delta$-cells demonstrated that the sum of these endocrine cell types relative to total pancreas cells was not altered in the E18.5 Dpy30 $\mathrm{N}$ pancreas compared to controls (Figure 2C-D). The relative proportion of $D p y 30 \Delta \mathrm{N}$ islet insulin ${ }^{+} \beta$-cells, glucagon ${ }^{+}$ $\alpha$-cells and somatostatin ${ }^{+} \delta$-cells was also unaffected both in E18.5 pancreas (Figure $2 \mathrm{E}$ ) and postnatally in P24 Dpy30 $\mathrm{N}$ pancreas (Figure 2F-G). Although there were no changes in islet endocrine cell proportions, we noted that the insulin staining in $D p y 30 \Delta \mathrm{N}$ islets appeared reduced compared to controls (Figure $2 \mathrm{~F}$ ). Further, quantification of $\mathrm{CHGA}^{+}$area at P24 revealed no changes in total endocrine cell area between the control and $D p y 30 \Delta \mathrm{N}$ pancreas (Figure $2 \mathrm{H}$ ). These data suggest that disruption of Dpy30 in NEUROG3 ${ }^{+}$progenitors does not affect the proportion of differentiated endocrine cells in the embryo or postnatal pancreas.

Dpy30 $\Delta \mathrm{N}$ mice develop hyperglycemia and impaired glucose tolerance

To investigate whether the postnatal islet reduction in $\mathrm{H} 3 \mathrm{~K} 4$ methylation had a biological effect in Dpy30 $\Delta \mathrm{N}$ mice, we first monitored body mass and random fed blood glucose levels. Daily tracking between P24 and P38 indicated that while body mass was not altered in male Dpy30 $\Delta N$ mice compared to controls (Figure 3A), mean ad libitum glycemia was over $18 \mathrm{mM}$ 
by P28 and worsened over time (Figure 3B). A similar trend was observed in female Dpy30 $4 \mathrm{~N}$ mice (Figure S1A-B). Following a 6 hour fast at P23, blood glucose levels were equivalent in control and Dpy30 $\Delta \mathrm{N}$ male mice (Figure S2A). Intraperitoneal glucose tolerance tests (IPGTTs) at this stage (P23) revealed a marginal increase to $\sim 19 \mathrm{mM}$ at 30 minutes, although blood glucose measurements at other time points were otherwise comparable to controls (Figure S2B). At P24, although fasting blood glucose levels remained similar between control and Dpy30 $\Delta \mathrm{N}$ male mice (Figure $3 \mathrm{C}$ ), blood glucose was significantly elevated in Dpy30 $\Delta \mathrm{N}$ males following an IP glucose challenge (Figure 3D). At P25, fasting glycemia levels were elevated to $\sim 12 \mathrm{mM}$ in Dpy30 $\mathrm{N}$ male mice (Figure S2C) and blood glucose levels were above the limit of detection (33.3 mM) at 15- and 30-minutes post-glucose injection (Figure S2D). Finally, we measured islet insulin content and detected a $\sim 40 \%$ reduction in insulin levels from P24 male Dpy30 $\triangle \mathrm{N}$ islets relative to controls (Figure $3 \mathrm{E}$ ). A $\sim 50 \%$ reduction in islet insulin content was also detected in female Dpy30 $\Delta \mathrm{N}$ mice (Figure S1C). These data suggest that $D p y 30 \Delta \mathrm{N}$ mice develop random and fasting hyperglycemia, impaired glucose tolerance and have decreased islet insulin content.

H3K4 trimethylation is necessary for the expression of mature pancreatic islet genes

To understand the underlying mechanism for hyperglycemia and impaired glucose tolerance in Dpy30 $\Delta \mathrm{N}$ mice, we next examined whether islet dysfunction was the result of reduced endocrine cell maturity. To assess islet maturation, islets from male Dpy30 $\Delta \mathrm{N}$ and control mice were collected at P24 and RNA-sequencing (RNA-seq) was performed. Differential gene expression analysis demonstrated that endocrine cell hormones (e.g. Gcg, Ins1, Ins2, Ppy and Sst) and genes involved in insulin secretion or $\beta$-cell maturation (e.g. Abcc8, Glp1r, Kcnj11, Slc2a2, Slc30a8 and Ucn3) were downregulated in Dpy30 $\Delta N$ islets compared to controls (Figure 4A-B). Interestingly, the glucagon receptor (Gcgr) was one of the most 
downregulated genes ( 16 -fold reduction) in $D p y 30 \Delta \mathrm{N}$ islets. Genes in the glucose-stimulated insulin secretion pathway were particularly affected by decreased H3K4 methylation in maturing pancreatic islets (Figure 4C). Elevated genes in Dpy30 $\Delta \mathrm{N}$ islets included genes associated with immature $\beta$-cells (e.g. Aldh1a3, Gast, Hk1/2, Ldha, Npy, Pdgfra, Rest and Slc16a1) and several genes involved in cell adhesion (e.g. Apoa1, Ccn3, Cldn2, Col16a1, Itga11 and Lamc3) (Figure 4A-B). RNA-seq analysis also revealed that neither mature islet transcription factors (e.g. Mafa, Neurod1, Nkx2-2, Nkx6-1, Pax6 and Pdx1) nor genes involved in mTOR signaling (e.g. Akt1, Mtor, Pdk1 and Rptor) were differentially expressed in Dpy30 $\mathrm{N}$ islets (Figure S3). GO term analysis indicated that genes involved in ion and transmembrane transport and hormone and insulin secretion were reduced in $D p y 30 \Delta N$ cells, while genes involved in extracellular matrix formation and cell adhesion were elevated (Figure 4D).

Transcription factor occupancy and histone modification status at downregulated, upregulated and stably expressed genes in Dpy30 $\Delta \mathrm{N}$ islets was examined using previously published adult mouse islet chromatin immunoprecipitation sequencing (ChIP-seq) data (Gutiérrez et al., 2017; Lu et al., 2018; Piccand et al., 2014; Swisa et al., 2017; Taylor et al., 2013; Tennant et al., 2013). The islet transcription factors NKX2-2, NKX6-1 and RFX6 were marginally depleted at upregulated genes (Figure 4E). We utilized ChromHMM to stratify the histone modification ChIP-seq data into chromatin states, including repressed (H3K27me3), unmarked, poised (H3K4me1/3), active (H3K4me1/3 and H3K27ac) and bivalent (H3K4me1 and H3K27me3) chromatin (Figure 4F). Histone modifications associated with active chromatin were relatively increased at the promoters of downregulated and stable genes (Figure 4G). In contrast, the cis-regulatory elements governing the upregulated genes were in an inactive chromatin state, with either unmarked histones or enrichment of repressive, bivalent or poised histone modifications (Figure 4G). Together, these results suggest that hyperglycemia and 
impaired glucose tolerance in Dpy30 $\mathrm{N}$ mice manifests from the reduced expression of genes required for islet $\beta$-cell maturity and glucose-stimulated insulin secretion.

\section{Failed activation of pro-endocrine cis-regulatory elements in Dpy30 $\mathrm{N}$ mice}

To explore whether the differentially expressed genes in P24 Dpy30 $\Delta N$ islets require distinct chromatin state changes during pancreatic endocrine cell development to become active, we assessed the histone modification profiles of the genes in Neurog $3^{\mathrm{HI}}$ cells compared to adult islets (Gutiérrez et al., 2017; Piccand et al., 2014; Swisa et al., 2017; Taylor et al., 2013; Tennant et al., 2013; Yu et al., 2018). Our analysis revealed that in Neurog $3^{\mathrm{HI}}$ endocrine progenitors downregulated, upregulated and stable genes had a similar H3K4me3 profile at their promoters; however, there was noticeably increased enrichment of H3K4me3 at downregulated in islets as compared to in Neurog $3^{\mathrm{HI}}$ endocrine progenitors (Figure 5A). The H3K4me1 profiles revealed that promoters of downregulated and upregulated genes were blocked in Neurog $3^{\mathrm{HI}}$ cells (Cheng et al., 2014), whereas H3K4me1-marked histones shifted away from the transcription start site (TSS) in adult islets (Figure 5B). H3K27ac enrichment profiles were relatively unchanged between Neurog $3^{\mathrm{HI}}$ cells and adult islets, more than for upregulated genes (Figure 5C). H3K27me3 profiles were also similar for downregulated, upregulated and stable genes in Neurog $3^{\mathrm{HI}}$ cells, although upregulated genes had modestly increased enrichment of the repressive H3K27me3 histone modification in adult islets (Figure 5D). Assessment of transitions from the chromatin states identified in Neurog $3^{\mathrm{HI}}$ endocrine progenitors to those identified in mature endocrine islet cells showed that an increased fraction of genes that were downregulated in $D p y 30 \Delta \mathrm{N}$ islets transitioned to an active chromatin state (H3K27ac and/or H3K4me1/3) during development (Figure 5E-F). Conversely, genes that were upregulated in Dpy30 $\Delta \mathrm{N}$ islets more frequently gained a repressive chromatin state (H3K27me3, bivalent or unmarked) in adult islets (Figure 5E-F). UCSC Genome Browser views 
at the TSS and cis-regulatory loci of GIp1r, S/c2a2 and S/c30a8 demonstrate acquisition of active histone marks during endocrine cell maturation at these loci (Figure 5G). Overall, these data suggest there is a marginal increase in the fraction of downregulated genes in $D p y 30 \Delta \mathrm{N}$ islets that acquire active histone modifications during development, while upregulated genes are more likely to acquire a repressive state.

H3K4 trimethylation is required for pancreatic endocrine cell maturation

To determine whether the endocrine cell terminal markers Ins1, Ins2, Gcg, Sst and Ppy that require activation during endocrine development fail to fully activate or instead lose expression in Dpy30 $\Delta \mathrm{N}$ islets, we used qPCR to quantify their expression at P7, P14 and P24. We found that expression of these markers at P7 was very similar between $D p y 30 \Delta \mathrm{N}$ and control islets (Figure 6A). The expression of all of these markers significantly increased in control islets by $\mathrm{P} 24$, but no increase was detected in $D p y 30 \Delta \mathrm{N}$ islets at P14 or P24 as compared to at P7 (Figure 6A). In contrast, Npy and Gast, which are known to have elevated expression in immature islets, were significantly increased at P24 in Dpy30 $\Delta \mathrm{N}$ islets as compared in control islets (Figure 6A). Staining pancreas sections from P24 control and Dpy30 $\Delta \mathrm{N}$ mice confirmed that gastrin protein levels were also elevated in $D p y 30 \Delta \mathrm{N}$ islets (Figure 6B). We next compared the expression of downregulated, upregulated and stable genes identified in our P24 islet RNA-seq analysis across endocrine cell differentiation and maturation. For this, we used previously published data from E13.5 Neurog $3^{\mathrm{HI}}$ endocrine progenitors and E17.5 INS1+ $\beta$-cells (Yu et al., 2018), as well as INS1+ $\beta$-cells from P1, P7, P14, P21 and P28 islets (Zeng et al., 2017). In agreement with our previous data, we found that an increased fraction of downregulated genes in Dpy30 $\Delta \mathrm{N}$ islets are normally activated during pancreatic $\beta$-cell maturation (Figure 6C). Combined, these data suggest that H3K4 
trimethylation is necessary for the appropriate activation of mature endocrine cell genes during postnatal islet functional maturation.

\section{Discussion}

TrxG complex proteins are enriched in mature islets (Tennant et al., 2015) and interact with the maturation factor MAFA in mature $\beta$-cells (Scoville et al., 2015), suggesting a role for TrxG complexes and/or H3K4 methylation in maintenance of islet identity. Deletion of the TrxG gene Ncoa6 in embryonic $\beta$-cells does not affect Mafa expression but results in reduced downstream activation of MAFA target genes and impaired glucose-stimulated insulin secretion (Scoville et al., 2015). Importantly, decreased gene expression was correlated with reductions in H3K4 trimethylation and RNA polymerase II (Pol II) at the TSS of affected genes. In addition, H3K4 trimethylation deposited by the SET7/9 histone methyltransferase was linked to transcriptional maintenance of genes involved in glucose-stimulated insulin secretion in primary islets (Deering et al., 2009). Together, these studies suggest that H3K4 trimethylation may play a role in maintaining $\beta$-cell gene expression, but whether $\mathrm{H} 3 \mathrm{~K} 4$ trimethylation is required during the process of endocrine cell maturation has not been examined.

In this study, we demonstrate that genetic inactivation of Dpy30 in NEUROG3 ${ }^{+}$cells does not alter the proportion of pancreatic endocrine progenitors or endocrine cells. Global loss of H3K4 trimethylation occurred postnatally during islet-cell maturation. By P28, Dpy30 $\Delta \mathrm{N}$ mice displayed elevated random and fasting glycemia, in addition to impaired glucose tolerance by P24. These phenotypes could not be explained by changes in Dpy30 $\Delta \mathrm{N}$ endocrine cell area or the relative proportions of islet cells. However, islet insulin content and expression of insulin and genes associated with insulin secretion and $\beta$-cell maturity were reduced in P24 Dpy30 $4 \mathrm{~N}$ islets. In addition, we detected impaired activation of Ins1 and Ins2 during the postnatal islet 
maturation period. Together, these data suggest that $\mathrm{H} 3 \mathrm{~K} 4$ trimethylation is required for normal islet-cell functional maturation.

Hyperglycemia and impaired glucose tolerance correlates with loss of islet H3K4 trimethylation

As discussed above, loss of endocrine cell H3K4 mono- and trimethylation was delayed in Dpy30 $\mathrm{N}$ mice. Although DPY30 was absent from $\mathrm{CHGA}^{+}$endocrine cells at E14.5, loss of H3K4me3 did not occur until P14. This difference is likely, at least in part, the result of failed H3K4me3 re-establishment during cell division. At the time when Dpy30 is genetically inactivated, NEUROG3 ${ }^{+}$cells exit the cell cycle and differentiate into endocrine cells (Miyatsuka et al., 2011). These cells remain non-proliferative until the early postnatal period when endocrine cell replication increases (Cleaver and MacDonald, 2010), suggesting that there is progressive loss of H3K4 methylation after each round of endocrine cell division. Of note, we observed no phenotype in Dpy30 $\mathrm{N}$ mice prior to the loss of H3K4 methylation, suggesting that loss of DPY30 itself has a minimal effect and that the impaired endocrine cell maturation in Dpy30 $\Delta \mathrm{N}$ mice is due to the absence of $\mathrm{H} 3 \mathrm{~K} 4$ methylation.

The loss of H3K4 methylation from Dpy30 $\mathrm{N}$ islets at P14 overlaps with the period of endocrine cell maturation. A key determinant of $\beta$-cell maturity is the ability to effectively respond to glucose, which includes efficient glucose transport and metabolism as well as regulated insulin secretion. During the first few weeks after birth, endocrine cells undergo functional maturation and develop glucose-stimulated hormone secretion by P14 (Blum et al., 2012; Liu and Hebrok, 2017; Pan and Wright, 2011). Further $\beta$-cell maturation is triggered by exposure to a carbohydrate-rich diet after weaning at P21 (Stolovich-Rain et al., 2015). The transition to glucose metabolism as the primary energy source exposes maturing islets to increased glucose levels, and this stimulates $\beta$-cell proliferation, enhances insulin secretion and promotes oxidative phosphorylation (Stolovich-Rain et al., 2015). Following weaning, Dpy30 $\Delta \mathrm{N}$ 
mice developed hyperglycemia and impaired glucose tolerance beginning at P24, suggesting that either glucose-stimulated insulin secretion, insulin levels or insulin action may be affected at this stage. Measurement of islet insulin content and our gene expression data confirmed that insulin levels were significantly reduced in P24 Dpy30 $4 \mathrm{~N}$ islets. In addition, we detected no significant difference in P24 islet area relative to controls, suggesting that hyperglycemia did not result from impaired $\beta$-cell proliferation. Instead, our data suggests that during a glucose challenge, Dpy30 $\Delta \mathrm{N}$ mice have insufficient insulin secretion to reduce blood glucose due to reduced levels of insulin.

Pancreatic endocrine cell maturation is impaired in Dpy30 $\Delta \mathrm{N}$ mice

Specification of the pancreatic endocrine lineage begins with activation of Neurog 3 in a subset of SOX9+ pancreas progenitors in the developing embryo. NEUROG3+ cells delaminate and migrate away from the trunk epithelium into the surrounding mesenchyme, where they eventually differentiate into endocrine cells and coalesce into mature spherical islet structures (Bastidas-Ponce et al., 2017). Extracellular matrix proteins such as cadherins, collagens, integrins and laminins have an essential role in cell migration and cell-cell adhesion during endocrine cell aggregation into islet clusters (Bastidas-Ponce et al., 2017; Dahl et al., 1996; Stendahl et al., 2009). Interestingly, we detected a disproportionate upregulation of many genes associated with the extracellular matrix and cell-cell adhesion, including Cldn2, Apoa1, Col16a1, Ccn3, Lamc3 and Itga11 in P24 Dpy30 $4 \mathrm{~N}$ islets, that play important roles in endocrine cell migration, isletogenesis, and maintenance of intercellular communication (Murtaugh et al., 2017).

The transition from immature to mature $\beta$-cells involves important gene expression changes, where genes exclusive to immature $\beta$-cells (e.g. Hk1, Ldha, Rest and Pdgfra) become repressed, and mature genes associated with insulin secretion machinery (e.g. Gck, Slc2a2 
and Slc30a8) are induced (Liu and Hebrok, 2017). In Dpy30 $\Delta \mathrm{N}$ islets, the expression of several mature genes required for glucose transport (Slc2a2), glucose sensing (Gck) and insulin secretion (Abcc8, Kcnj11) was significantly reduced, in addition to the mature $\beta$-cell marker Ucn3 (Blum et al., 2012). Meanwhile, several genes associated with endocrine cell immaturity, such as Aldh1a3, Gast, Hk2, Pdgfra and Rest were elevated in Dpy30 $\Delta$ N islets. In addition, we detected GAST+ endocrine cells exclusively in P24 Dpy30 $4 \mathrm{~N}$ islets. Furthermore, transcript levels of islet hormones (e.g. Ins1, Ins2, Gcg, Ppy and Sst) were also significantly reduced in Dpy30 $4 \mathrm{~N}$ islets. Together, these data strongly suggest that at P24 Dpy30 $4 \mathrm{~N}$ islet cells are still in an immature-like state. It is important to note that this immaturity is without significant changes to the expression of key islet transcription factors (e.g. Mafa, Neurod1, Nkx2-2, Nkx61, Pax6 and Pdx1) (Figure S3). We also did not observe significant gene expression changes in the mTOR pathway in Dpy30 $\mathrm{N}$ islets (Figure S3), which plays an important role in islet functional maturation (Ni et al., 2017; Sinagoga et al., 2017).

H3K4 methylation is acquired at mature $\beta$-cell genes during functional maturation

We found that genes upregulated in P24 Dpy30 $4 \mathrm{~N}$ islets as compared were slightly more likely to become H3K27me3 marked or "unmarked" in islets as compared to in Neurog $3^{\mathrm{HI}}$ cells. This agrees with our gene expression data and suggests a subset of these genes are genes that are normally more abundant in progenitors or immature endocrine cells and that are generally "turned-off" in mature pancreas endocrine cells. It is less clear why some genes, specifically endocrine cell terminal markers such as Ins1, Ins2, Gcg, Sst and Ppy, and genes with functional relevance in $\beta$-cells fail to be activated in Dpy30 $\Delta \mathrm{N}$ endocrine cells, while other genes are unaffected. Our analysis of the chromatin state changes at these genes from Neurog $3^{\mathrm{HI}}$ to adult islets suggest they are more likely to be activated and to gain active chromatin marks, but otherwise are very similar in chromatin state to genes unaffected by the 
loss of H3K4me3. Other groups have found similar results, and have found that H3K4me3 loss primarily affects the expression of lineage-specific genes (Benayoun et al., 2014; Chen et al., 2015). Why this is the case, and whether H3K4 trimethylation is required purely to activate such genes, or if it is also essential to maintain lineage-specific expression is unknown and warrants further investigation.

Regardless, the results in this study suggest that $\mathrm{H} 3 \mathrm{~K} 4$ trimethylation is required for the expression of pancreatic islet genes involved in endocrine cell functional maturation. This conclusion is supported by evidence that $\mathrm{H} 3 \mathrm{~K} 4$ methylation is established at these genes during the endocrine cell maturation period. Overall, our data suggests that islet endocrine cells do not completely mature in the absence of $\mathrm{H} 3 \mathrm{~K} 4$ methylation.

\section{Acknowledgements}

The authors would like to thank the staff of the Animal Care Facility at BCCHRI for daily maintenance of the mouse colonies. Funding was provided by British Columbia Children's Hospital Research Institute, and the Natural Sciences and Engineering Research Council of Canada (RGPIN-2016-04292) and the Canadian Institute for Health Research (RN310864 375894).

\section{Author Contributions}

Experiments were conducted by S.A.C., J.B., C.L.M., B.V. and T.L.S. and conceptualized by S.A.C. and B.G.H.; funding and supervision was provided by B.G.H.; the manuscript was written by S.A.C and B.G.H.

\section{Declaration of Interests}

The authors declare no competing interests. 


\section{Experimental Procedures}

\section{Mouse Strains and Embryo Collection}

All mice were held at the British Columbia Children's Hospital Research Institute Animal Care Facility and ethical procedures were followed according to protocols approved by the University of British Columbia Animal Care Committee. All mice were maintained on a regular chow diet ad libitum and housed up to 5 mice per cage on a 12-hour light/dark cycle. Timed matings were used to determine embryonic stages and the morning of vaginal plug discovery was considered embryonic day 0.5 (E0.5). Previously generated Dpy30flox/flox mice (Campbell et al., 2019) were crossed to Neurog3-Cre driver mice (Schonhoff et al., 2004) to obtain conditional deletion of Dpy30 exon 4 in endocrine progenitors. In all studies, knockout mice (Dpy30 4 N; Neurog3-Cre;

$\left.D p y 30^{\text {flox/flox }}\right)$ were compared to Cre-negative littermate controls (Dpy30 flox/flox or Dpy30 flox/wt $)$. At noon on the day of the experimentally determined time point (e.g., E14.5), embryos were harvested by hysterectomy, dissected under an Olympus dissecting microscope in ice-cold phosphate buffered saline (PBS) and tail clippings were taken for genotyping. All knockout embryos were stained for DPY30 and/or H3K4 methylation to determine recombination efficiency prior to further analysis. Embryos with insufficient loss of DPY30 or H3K4 methylation $(<80 \%)$ were not studied. For all experiments, sex-specific differences were not anticipated and embryo sex was not determined.

\section{Pancreas and Islet Isolations}

Mice were anesthetized with isoflurane inhalation and checked for toe pinch reflexes prior to euthanasia by cervical dislocation. To open the chest cavity, two lateral incisions were made in the abdomen away from the midline, followed by medial incisions up and down the midline and through the ribcage and diaphragm. The pancreas was dissected by cutting all connections to 
the spleen, stomach, intestine and liver before placing the tissue directly into $4 \%$ PFA in PBS on ice, followed by fixation overnight at $4^{\circ} \mathrm{C}$.

For islet isolations, mice were euthanized by decapitation and blood was drained. The common bile duct was clamped at the duodenum and a $30 \mathrm{G}$ needle was used for perfusion of 3 mL Collagenase XI (1000 U/mL, Sigma-Aldrich) in Hank's Balanced Salt Solution (HBSS) into the common bile duct. The pancreas was dissected and further enzymatically digested in an additional $2 \mathrm{~mL}$ Collagenase $\mathrm{XI}$ for 15 minutes in a $40^{\circ} \mathrm{C}$ water bath before 3 minutes of mechanical shaking. Pancreas tissue was washed twice with $25 \mathrm{~mL}$ HBSS with $1 \mathrm{mM} \mathrm{CaCl}$ before filtering through a 40 or $70 \mu \mathrm{m}$ cell strainer (depending on mouse age). Islets collected on the strainer were inverted and rinsed into a petri dish with RPMl 1640 media (11 mM Dglucose) supplemented with 10\% FBS, $50 \mathrm{U} / \mathrm{mL}$ penicillin/streptomycin and $2 \mathrm{mM}$ L-glutamine, and either recovered overnight at $37^{\circ} \mathrm{C}$ in a $5 \% \quad \mathrm{CO}_{2}$ humidified incubator or immediately handpicked for experiments under a dissecting microscope.

\section{Tissue Processing and Histology}

Embryonic and pancreatic tissue was fixed at $4^{\circ} \mathrm{C}$ in $4 \%$ PFA overnight (whole embryos) or for 5 hours (dissected stomach, pancreas, spleen and intestine $\geq E 15.5$ ). All tissue was processed through a series of graded ethanol and xylene de-hydration steps before embedding in paraffin wax. Briefly, fixed embryos and tissues were washed 3x 10 minutes in PBS and processed in cassettes through $50 \%$ ethanol (embryos only), $70 \%$ ethanol, $2 \times 30$ minutes of $95 \%$ and $100 \%$ ethanol, $2 \times 30$ minutes of xylene, followed by $2 \times 1$ hour in melted paraffin. Embryonic or pancreatic tissue was cut into $5 \mu \mathrm{m}$ sagittal sections using a Microtome and mounted onto Superfrost Plus slides. 
bioRxiv preprint doi: https://doi.org/10.1101/2020.11.29.402990; this version posted November 30, 2020. The copyright holder for this preprint (which was not certified by peer review) is the author/funder, who has granted bioRxiv a license to display the preprint in perpetuity. It is made available under aCC-BY-NC-ND 4.0 International license.

Immunostaining, Imaging and Analysis

Paraffin slides were processed through graded xylene and ethanol re-hydration steps, followed by a 10 minute heat-induced antigen retrieval (10 mM sodium citrate, $\mathrm{pH} 6.0$ ) at $95^{\circ} \mathrm{C}$ and 1 hour blocking (5\% FBS in PBS) at room temperature. Briefly, slides were processed through 3x 5 minutes xylene, 2x 5 minutes 100\% ethanol, 5 minutes 95\% ethanol, 5 minutes $70 \%$ ethanol and 10 minutes in PBS on a shaker prior to antigen retrieval. Slides were cooled for 5 minutes under cold running tap water and washed for 5 minutes each in de-ionized water and PBS on a shaker before circumscribing with a Super PAP pen (Thermo Fisher Scientific) and blocking. Primary antibodies were incubated at $4^{\circ} \mathrm{C}$ overnight with dilutions in blocking solution (see Table below for antibody information). The following day, slides were washed $3 \times 10$ minutes in PBS and incubated with secondary antibodies in PBS for 1 hour at room temperature in a humidified dark chamber. Finally, slides were washed 3x 10 minutes in PBS before mounting with Prolong Gold mounting solution. Slides were imaged on a Leica TCS SP8 Confocal microscope or tiled on an Olympus Bx61 microscope and analyzed using CellProfiler software with custom pipelines.

\begin{tabular}{|l|l|l|l|l|}
\hline Antibody & Host Species & Manufacturer & Catalog \# & Dilution \\
\hline Chromogranin A & Mouse & Santa Cruz & sc-393941 & $1: 100$ \\
\hline DPY30 & Rabbit & Abcam & ab214010 & $1: 500$ \\
\hline DPY30 & Rabbit & Bethyl & A304-296A & $1: 10,000$ \\
\hline DPY30 & Rabbit & Atlas Antibodies & HPA043761 & $1: 1000$ \\
\hline Gastrin & Goat & Santa Cruz & sc-7783 & $1: 50$ \\
\hline Glucagon & Rabbit & Santa Cruz & sc-13091 & $1: 500$ \\
\hline Glucagon & Mouse & Sigma-Aldrich & G6254 & $1: 2000$ \\
\hline H3K4me1 & Rabbit & Abcam & ab8895 & $1: 1000$ \\
\hline H3K4me3 & Rabbit & Abcam & ab8580 & $1: 1000$ \\
\hline H3K4me3 & Rabbit & Cell Signaling & C42D8 & $1: 1000$ \\
\hline Insulin & Guinea Pig & Abcam & ab7842 & $1: 1000$ \\
\hline Insulin & Guinea Pig & Agilent & IR-002 & $1: 4$ \\
\hline NEUROG3 & Mouse & DSHB & F25A1B3-c & $1: 100$ \\
\hline Somatostatin & Goat & Santa Cruz & Sc-7819 & $1: 1000$ \\
\hline SOX9 & Rabbit & Millipore & AB5535 & $1: 2000$ \\
\hline DAPI & & Thermo Fisher & D9542 & $1: 5000$ \\
& & Scientific & & \\
\hline
\end{tabular}




\begin{tabular}{|c|c|c|c|c|}
\hline Antibody & Host Species & Manufacturer & Catalog \# & Dilution \\
\hline TOPRO-3 & & $\begin{array}{l}\text { Thermo } \quad \text { Fisher } \\
\text { Scientific }\end{array}$ & T3605 & $1: 5000$ \\
\hline $\begin{array}{l}\text { Alexa Fluor } 488 \\
\text { anti-Rabbit }\end{array}$ & Donkey & $\begin{array}{ll}\text { Thermo } & \text { Fisher } \\
\text { Scientific } & \end{array}$ & A-21206 & $1: 500$ \\
\hline $\begin{array}{l}\text { Alexa Fluor } 555 \\
\text { anti-Guinea Pig }\end{array}$ & Goat & $\begin{array}{ll}\text { Thermo } & \text { Fisher } \\
\text { Scientific } & \end{array}$ & A-21435 & $1: 500$ \\
\hline $\begin{array}{l}\text { Alexa Fluor } 546 \\
\text { anti-Mouse }\end{array}$ & Goat & $\begin{array}{ll}\text { Thermo } & \text { Fisher } \\
\text { Scientific } & \\
\end{array}$ & A-11003 & $1: 500$ \\
\hline $\begin{array}{l}\text { Alexa Fluor } 488 \\
\text { anti-Goat }\end{array}$ & Donkey & $\begin{array}{ll}\text { Thermo } & \text { Fisher } \\
\text { Scientific } & \end{array}$ & A-11055 & $1: 500$ \\
\hline $\begin{array}{l}\text { Alexa Fluor } 647 \\
\text { anti-Mouse }\end{array}$ & Donkey & $\begin{array}{ll}\text { Thermo } & \text { Fisher } \\
\text { Scientific } & \\
\end{array}$ & A-31571 & $1: 500$ \\
\hline $\begin{array}{l}\text { Alexa Fluor } 594 \\
\text { anti-Rabbit }\end{array}$ & Donkey & $\begin{array}{ll}\text { Thermo } & \text { Fisher } \\
\text { Scientific } & \end{array}$ & A-21207 & $1: 500$ \\
\hline
\end{tabular}

Morphometric and Intensity analysis

Cell quantifications were determined by taking serial sections at set intervals throughout the entire embryonic (every 30-60 $\mu \mathrm{m}$ ) and postnatal (every $90 \mu \mathrm{m}$ ) pancreas. At least 10 images per replicate were captured on a Leica TCS SP8 Confocal microscope. Images were analyzed using CellProfiler software to quantify relative cell fractions or H3K4me3 immunostaining intensity. The number of NEUROG3 ${ }^{+}$nuclei was determined manually. Total $\mathrm{CHGA}^{+}$area in the P24 pancreas was determined from staining islets for CHGA on serial sections through the entire pancreas spaced $90 \mu \mathrm{m}$ apart. Images were tiled on an Olympus Bx61 microscope and analyzed relative to total pancreatic area using CellProfiler.

\section{Western Blot Analysis}

Islets were lysed for 5 minutes at $95^{\circ} \mathrm{C}$ in Laemmli sample buffer (2\% SDS, $10 \%$ glycerol, $60 \mathrm{mM}$ Tris pH 6.8) containing $1 \mathrm{mM} \mathrm{NaF}, 1 \mathrm{mM}$ PMSF and protease inhibitor cocktail (Roche). The Pierce BCA kit (Thermo Fisher Scientific) was used to determine lysate total protein concentrations and $5 \mu \mathrm{g}$ protein was re-boiled for 5 minutes with $5 \% \beta$-mercaptoethanol. Proteins were separated on $4-15 \%$ acrylamide gels and transferred for 60 minutes at $12.0 \mathrm{~V}$ to 
PVDF membranes (Millipore). Membranes were blocked in 5\% BSA in TBS (20 mM Tris pH 7.6, $150 \mathrm{mM} \mathrm{NaCl}$ ) containing 0.1\% Tween-20 (TBS-T) for 1 hour at room temperature before overnight incubation at $4^{\circ} \mathrm{C}$ with primary antibodies in $5 \%$ BSA/TBS-T. Primary antibodies were as follows: mouse anti-actin (DSHB, catalog \# JLA20-c, 1:2500) and rabbit anti-H3K4me3 (CST, catalog \# 9751, 1:1000). Membranes were washed 3x 10 minutes in TBS-T before incubated in secondary antibodies for 1 hour at room temperature. Secondary antibodies were as follows: HRP-conjugated anti-rabbit IgG (CST, catalog \# 7074, 1:10,000) and HRPconjugated anti-mouse IgG (Jackson Immunoresearch, catalog \# 115-035-174 1:10,000). Membranes were washed 3x 10 minutes in TBS-T and signals were detected using ECL reagent and radiographic film. Antibodies were then stripped in mild stripping buffer (200 mM glycine $0.1 \%$ SDS, $1 \%$ Tween-20, $\mathrm{pH} 2.2$ ) for 20 minutes at room temperature and washed $4 \mathrm{x}$ 10 minutes in TBS-T. The membrane was re-blocked and probed with rabbit anti-H3K4me1 (Abcam, catalog \# 8895, 1:100,000), then re-stripped, blocked and probed with rabbit anti-H3 (Abcam, catalog \# ab1791, 1:250,000). The resulting signals were quantified using ImageJ.

\section{Blood Glucose and Islet Insulin Measurements}

Mice were monitored after weaning at P21 for body mass and random blood glucose by a OneTouch ${ }^{\circledR}$ Ultra ${ }^{\circledR} 2$ glucometer. For intraperitoneal glucose tolerance tests (IPGTTs), mice were fasted for 6 hours prior to IP injection of $2 \mathrm{~g} / \mathrm{kg} 20 \%$ D-glucose (Sigma-Aldrich) in water with a $26 \mathrm{G}$ needle. Blood glucose measurements were obtained from the tail vein prior to injection $\left(T_{0}\right)$ and 15, 30, 60 and 120 minutes after injection. For islet insulin content, isolated islets were lysed in RIPA buffer (25 mM Tris pH 7.6, $150 \mathrm{mM} \mathrm{NaCl}, 1 \% \mathrm{NP} 40,1 \%$ sodium deoxycholate and $0.1 \%$ SDS) for 5 minutes at $95^{\circ} \mathrm{C}$. Islet insulin content was determined from the lysate by the Mouse Ultrasensitive Insulin ELISA kit (ALPCO) and a Spectramax 190 plate 
reader (Molecular Devices). Insulin measurements were normalized to islet lysate DNA concentration determined by the Qubit dsDNA HS Assay (Thermo Fisher Scientific).

\section{RNA Extraction and qPCR Analysis}

RNA was extracted from lysed cells by pipetting in TRIzol reagent (Thermo Fisher Scientific) and combined with $1 / 5$ the total volume of chloroform. Samples were inverted 10x before centrifugation at $12,000 x g$ for 15 minutes at $4^{\circ} \mathrm{C}$. The aqueous layer was mixed with an equal volume of ice-cold $70 \%$ ethanol and further processed with the PureLink RNA Mini Kit (Ambion). Complementary DNA (cDNA) was generated using SuperScript III Reverse Transcriptase (Thermo Fisher Scientific) and qPCR experiments were carried out using 0.25-2 $\mu \mathrm{L}$ of cDNA per reaction. Both Fast SYBR Green and TaqMan chemistry (Thermo Fisher Scientific) was used with purchased or custom designed primers (Primer3) to detect exon-intron boundaries. Samples were loaded onto 384-well plates in triplicate and run on a ViiA 7 Real-Time PCR system (Thermo Fisher Scientific) where gene expression was normalized to $\beta$-actin and determined using the $\Delta \Delta \mathrm{C}_{\mathrm{t}}$ formula.

\section{RNA-Sequencing Analysis}

Islets from 3 control and 3 Dpy30 $\Delta \mathrm{N}$ male mice were isolated at P24 and 100-200 islets per mouse were handpicked into $1 \mathrm{~mL}$ of TRIzol reagent (Thermo Fisher Scientific). Extracted RNA was treated with TURBO DNase I (Thermo Fisher Scientific) for 20 minutes at $37^{\circ} \mathrm{C}$ to remove genomic DNA. For each sample at P24, mRNA was enriched from 1000 ng of total RNA using the NEBNext Poly(A) mRNA Magnetic Isolation Module (NEB) and 6 cDNA libraries were prepared with the NEBNext Ultra II Directional RNA Library Prep Kit for Illumina (NEB) with 9 amplification cycles. Indexed libraries were analyzed for size distribution using the Agilent Bioanalyzer High Sensitivity DNA chip and quantified using the Qubit dsDNA HS Assay 
(Thermo Fisher Scientific). Pooled libraries were sequenced on an Illumina NextSeq500 platform for $2 \times 43$ nucleotide paired-end reads.

For analysis of islet RNA-seq libraries, the resulting FastQ sequencing files were combined, filtered (phred33) and trimmed to remove adapters with Trimmomatic (Bolger et al., 2014). Salmon (Patro et al., 2017) was used to quasi-map, assemble and quantify transcripts using the mouse GRCm38/NVM24 transcriptome. Differential gene expression analysis was performed using DEseq2 (Love et al., 2014) in R, with the apeglm algorithm used to shrink log fold changes (Zhu et al., 2019). Gene set enrichment analysis was performed with g:Profiler (Raudvere et al., 2019).

Previously published RNA-seq data from E13.5 Neurog $3^{\mathrm{HI}}$ endocrine progenitors and E17.5 INS1+ pancreatic $\beta$-cells (Yu et al., 2018) was combined with RNA-seq data from P1, P7, P14, P21 and P28 pancreatic islets (Zeng et al., 2017) and was processed as described above. The transcripts per million were compiled to create a developmental timeline.

\section{ChIP-Sequencing Analysis}

We used published ChIP-seq data (H3K4me3, H3K4me1, H3K27ac and H3K27me3) from E13.5 Neurog $3^{\mathrm{HI}}$ and adult islets (Lu et al., 2018; Tennant et al., 2013) and previously published transcription factor binding data for FOXA2, MAFA, PDX1 and NEUROD1 (Tennant et al., 2013), and for NKX2-2 (Gutiérrez et al., 2017), NKX6-1 (Taylor et al., 2013), PAX6 (Swisa et al., 2017), RFX6 (Piccand et al., 2014). All data were mapped with bowtie2 to the GRCm38/mm10 genome and peaks for the transcription factors called with MACS2. We used Repitools to plot the distribution of each histone mark at the transcriptional start sites (TSS, \pm $3 \mathrm{~kb}$ ) of the differentially expressed gene sets. We used ChromHMM (Ernst and Kellis, 2012) using a $k$-value of 10 to characterize the chromatin states of Neurog $3^{\mathrm{HI}}$ and islet cells. We determined the percent coverage of each state at the TSS ( $\pm 2 \mathrm{~kb})$ of the differentially expressed 
gene sets using the coverage function of bedtools2 (version 2.29.2). Based on the hierarchy of chromatin states and highest percent coverage, each gene was defined a chromatin state from the Neurog $3^{\mathrm{HI}}$ and islet data sets.

\section{Statistics}

Data are expressed as mean \pm standard deviation (SD) unless otherwise specified and all experiments were carried out at minimum in triplicate. Statistical analyses were performed using GraphPad Prism 8 Software. Statistical significance was determined using unpaired, twotailed Student's t-tests for comparisons between two groups, and two-way ANOVA with Sidak's multiple comparisons post-hoc tests were used for repeated measures comparisons between more than two groups (unless otherwise specified), with * indicating $P<0.05$, ** indicating $P<$ $0.01,{ }^{* * *}$ indicating $P<0.001$ and ${ }^{* * * *}$ indicating $P<0.0001$. 


\section{References}

Bastidas-Ponce, A., Scheibner, K., Lickert, H., and Bakhti, M. (2017). Cellular and molecular mechanisms coordinating pancreas development. Development 144, 2873-2888.

Benayoun, B.A., Pollina, E.A., Ucar, D., Mahmoudi, S., Karra, K., Wong, E.D., Devarajan, K., Daugherty, A.C., Kundaje, A.B., Mancini, E., et al. (2014). H3K4me3 breadth is linked to cell identity and transcriptional consistency. Cell 158, 673-688.

Bertero, A., Madrigal, P., Galli, A., Hubner, N.C., Moreno, I., Burks, D., Brown, S., Pedersen, R.A., Gaffney, D., Mendjan, S., et al. (2015). Activin/nodal signaling and NANOG orchestrate human embryonic stem cell fate decisions by controlling the H3K4me3 chromatin mark. Genes Dev 29, 702-717.

Blum, B., Hrvatin, S., Schuetz, C., Bonal, C., Rezania, A., and Melton, D.A. (2012). Functional beta-cell maturation is marked by an increased glucose threshold and by expression of urocortin 3. Nat Biotechnol 30, 261-264.

Bochyńska, A., Lüscher-Firzlaff, J., and Lüscher, B. (2018). Modes of Interaction of KMT2 Histone H3 Lysine 4 Methyltransferase/COMPASS Complexes with Chromatin. Cells 7.

Bolger, A.M., Lohse, M., and Usadel, B. (2014). Trimmomatic: a flexible trimmer for Illumina sequence data. Bioinformatics 30, 2114-2120.

Campbell, S.A., and Hoffman, B.G. (2016). Chromatin Regulators in Pancreas Development and Diabetes. Trends Endocrinol. Metab. 27, 142-152.

Campbell, S.A., McDonald, C.L., Krentz, N.A.J., Lynn, F.C., and Hoffman, B.G. (2019). TrxG Complex Catalytic and Non-catalytic Activity Play Distinct Roles in Pancreas Progenitor Specification and Differentiation. Cell Rep. 28, 1830-1844.e1836.

Chen, K., Chen, Z., Wu, D., Zhang, L., Lin, X., Su, J., Rodriguez, B., Xi, Y., Xia, Z., Chen, X., et al. (2015). Broad H3K4me3 is associated with increased transcription elongation and enhancer activity at tumor-suppressor genes. Nat. Genet. 47, 1149-1157.

Cheng, J., Blum, R., Bowman, C., Hu, D., Shilatifard, A., Shen, S., and Dynlacht, B.D. (2014). A Role for H3K4 Monomethylation in Gene Repression and Partitioning of Chromatin Readers. Mol Cell 53, 979-992.

Cleaver, O., and MacDonald, R.J. (2010). Developmental Molecular Biology of the Pancreas. In Pancreatic Cancer, pp. 71-117.

Dahl, U., Sjødin, A., and Semb, H. (1996). Cadherins regulate aggregation of pancreatic betacells in vivo. Development 122, 2895-2902.

Deering, T.G., Ogihara, T., Trace, A.P., Maier, B., and Mirmira, R.G. (2009).

Methyltransferase Set7/9 maintains transcription and euchromatin structure at islet-enriched genes. Diabetes 58, 185-193. 
Dhawan, S., Tschen, S.-I., Zeng, C., Guo, T., Hebrok, M., Matveyenko, A., and Bhushan, A. (2015). DNA methylation directs functional maturation of pancreatic $\beta$ cells. J. Clin. Invest. $125,2851-2860$.

Dorighi, K.M., Swigut, T., Henriques, T., Bhanu, N.V., Scruggs, B.S., Nady, N., Still, C.D., Garcia, B.A., Adelman, K., and Wysocka, J. (2017). MII3 and Mll4 Facilitate Enhancer RNA Synthesis and Transcription from Promoters Independently of H3K4 Monomethylation. Mol Cell 66, 568-576.e4.

Ernst, J., and Kellis, M. (2012). ChromHMM: automating chromatin-state discovery and characterization. Nat Meth 9, 215-216.

Gutiérrez, G.D., Bender, A.S., Cirulli, V., Mastracci, T.L., Kelly, S.M., Tsirigos, A., Kaestner, K.H., and Sussel, L. (2017). Pancreatic $\beta$ cell identity requires continual repression of non- $\beta$ cell programs. J. Clin. Invest. 127, 244-259.

Haddad, J.F., Yang, Y., Takahashi, Y.-H., Joshi, M., Chaudhary, N., Woodfin, A.R., Benyoucef, A., Yeung, S., Brunzelle, J.S., Skiniotis, G., et al. (2018). Structural Analysis of the Ash2L/Dpy-30 Complex Reveals a Heterogeneity in H3K4 Methylation. Structure 26, 1594-1603.e1594.

Heintzman, N.D., Hon, G.C., Hawkins, R.D., Kheradpour, P., Stark, A., Harp, L.F., Ye, Z., Lee, L.K., Stuart, R.K., Ching, C.W., et al. (2009). Histone modifications at human enhancers reflect global cell-type-specific gene expression. Nature 459, 108-112.

Heintzman, N.D., Stuart, R.K., Hon, G., Fu, Y., Ching, C.W., Hawkins, R.D., Barrera, L.O., Van Calcar, S., Qu, C., Ching, K.A., et al. (2007). Distinct and predictive chromatin signatures of transcriptional promoters and enhancers in the human genome. Nat. Genet. 39, 311-318.

Hödl, M., and Basler, K. (2012). Transcription in the absence of histone H3.2 and H3K4 methylation. Curr. Biol. 22, 2253-2257.

Jensen, J., Heller, R.S., Funder-Nielsen, T., Pedersen, E.E., Lindsell, C., Weinmaster, G., Madsen, O.D., and Serup, P. (2000). Independent development of pancreatic alpha- and beta-cells from neurogenin3-expressing precursors: a role for the notch pathway in repression of premature differentiation. Diabetes 49, 163-176.

Kieffer, T.J. (2016). Closing in on Mass Production of Mature Human Beta Cells. Cell Stem Cell 18, 699-702.

Larsen, H.L., and Grapin-Botton, A. (2017). The molecular and morphogenetic basis of pancreas organogenesis. Semin. Cell Dev. Biol. 66, 51-68.

Liu, J.S.E., and Hebrok, M. (2017). All mixed up: defining roles for $\beta$-cell subtypes in mature islets. Genes Dev 31, 228-240.

Love, M.I., Huber, W., and Anders, S. (2014). Moderated estimation of fold change and dispersion for RNA-seq data with DESeq2. Genome Biol. 15, 550. 
Lu, T.T.-H., Heyne, S., Dror, E., Casas, E., Leonhardt, L., Boenke, T., Yang, C.-H., Sagar, Arrigoni, L., Dalgaard, K., et al. (2018). The Polycomb-Dependent Epigenome Controls $\beta$ Cell Dysfunction, Dedifferentiation, and Diabetes. Cell Metab. 27, 1294-1308.e1297.

Miyatsuka, T., Kosaka, Y., Kim, H., and German, M.S. (2011). Neurogenin3 inhibits proliferation in endocrine progenitors by inducing Cdkn1a. Proc. Natl. Acad. Sci. U.S.a. 108, 185-190.

Murtaugh, L.C., Cleaver, O., and MacDonald, R.J. (2017). Developmental Molecular Biology of the Pancreas. In Pancreatic Cancer, pp. 1-57.

Ni, Q., Gu, Y., Xie, Y., Yin, Q., Zhang, H., Nie, A., Li, W., Wang, Y., Ning, G., Wang, W., et al. (2017). Raptor regulates functional maturation of murine beta cells. Nature Communications $8,1-13$.

Pan, F.C., and Wright, C. (2011). Pancreas organogenesis: from bud to plexus to gland. Dev. Dyn. 240, 530-565.

Patro, R., Duggal, G., Love, M.I., Irizarry, R.A., and Kingsford, C. (2017). Salmon provides fast and bias-aware quantification of transcript expression. Nat Meth 14, 417-419.

Pérez-Lluch, S., Blanco, E., Tilgner, H., Curado, J., Ruiz-Romero, M., Corominas, M., and Guigó, R. (2015). Absence of canonical marks of active chromatin in developmentally regulated genes. Nat. Genet. 47, 1158-1167.

Piccand, J., Strasser, P., Hodson, D.J., Meunier, A., Ye, T., Keime, C., Birling, M.-C., Rutter, G.A., and Gradwohl, G. (2014). Rfx6 maintains the functional identity of adult pancreatic $\beta$ cells. Cell Rep. 9, 2219-2232.

Raudvere, U., Kolberg, L., Kuzmin, I., Arak, T., Adler, P., Peterson, H., and Vilo, J. (2019). g:Profiler: a web server for functional enrichment analysis and conversions of gene lists (2019 update). Nucleic Acids Res. 47, W191-W198.

Rickels, R., Herz, H.-M., Sze, C.C., Cao, K., Morgan, M.A., Collings, C.K., Gause, M., Takahashi, Y.-H., Wang, L., Rendleman, E.J., et al. (2017). Histone H3K4 monomethylation catalyzed by Trr and mammalian COMPASS-like proteins at enhancers is dispensable for development and viability. Nat. Genet. 49, 1647-1653.

Schaffer, A.E., Taylor, B.L., Benthuysen, J.R., Liu, J., Thorel, F., Yuan, W., Jiao, Y., Kaestner, K.H., Herrera, P.L., Magnuson, M.A., et al. (2013). Nkx6.1 controls a gene regulatory network required for establishing and maintaining pancreatic Beta cell identity. PLoS Genet 9 , e1003274.

Schonhoff, S.E., Giel-Moloney, M., and Leiter, A.B. (2004). Neurogenin 3-expressing progenitor cells in the gastrointestinal tract differentiate into both endocrine and nonendocrine cell types. Dev. Biol. 270, 443-454.

Schuettengruber, B., Bourbon, H.-M., Di Croce, L., and Cavalli, G. (2017). Genome Regulation by Polycomb and Trithorax: 70 Years and Counting. Cell 171, 34-57. 
Scoville, D.W., Cyphert, H.A., Liao, L., Xu, J., Reynolds, A., Guo, S., and Stein, R. (2015). MLL3 and MLL4 Methyltransferases Bind to the MAFA and MAFB Transcription Factors to Regulate Islet $\beta$-Cell Function. Diabetes 64, 3772-3783.

Sinagoga, K.L., Stone, W.J., Schiesser, J.V., Schweitzer, J.I., Sampson, L., Zheng, Y., and Wells, J.M. (2017). Distinct roles for the mTOR pathway in postnatal morphogenesis, maturation and function of pancreatic islets. Development 144, 2402-2414.

Stendahl, J.C., Kaufman, D.B., and Stupp, S.I. (2009). Extracellular matrix in pancreatic islets: relevance to scaffold design and transplantation. Cell Transplant 18, 1-12.

Stolovich-Rain, M., Enk, J., Vikesa, J., Nielsen, F.C., Saada, A., Glaser, B., and Dor, Y. (2015). Weaning triggers a maturation step of pancreatic $\beta$ cells. Dev Cell 32, 535-545.

Swisa, A., Avrahami, D., Eden, N., Zhang, J., Feleke, E., Dahan, T., Cohen-Tayar, Y., Stolovich-Rain, M., Kaestner, K.H., Glaser, B., et al. (2017). PAX6 maintains $\beta$ cell identity by repressing genes of alternative islet cell types. J. Clin. Invest. 127, 230-243.

Taylor, B.L., Liu, F.-F., and Sander, M. (2013). Nkx6.1 is essential for maintaining the functional state of pancreatic beta cells. Cell Rep. 4, 1262-1275.

Tennant, B.R., Robertson, A.G., Kramer, M., Li, L., Zhang, X., Beach, M., Thiessen, N., Chiu, R., Mungall, K., Whiting, C.J., et al. (2013). Identification and analysis of murine pancreatic islet enhancers. Diabetologia 56, 542-552.

Tennant, B.R., Hurley, P., Dhillon, J., Gill, A., Whiting, C., and Hoffman, B.G. (2015). The TrxG Complex Mediates Cytokine Induced De Novo Enhancer Formation in Islets. PLoS ONE 10, e0141470.

van der Meulen, T., Donaldson, C.J., Cáceres, E., Hunter, A.E., Cowing-Zitron, C., Pound, L.D., Adams, M.W., Zembrzycki, A., Grove, K.L., and Huising, M.O. (2015). Urocortin3 mediates somatostatin-dependent negative feedback control of insulin secretion. Nat. Med. 21, 769-776.

Xie, G., Lee, J.-E., McKernan, K., Park, Y.-K., Jang, Y., Liu, C., Peng, W., and Ge, K. (2020). MLL3/MLL4 methyltransferase activities regulate embryonic stem cell differentiation independent of enhancer H3K4me1. bioRxiv 18, 1035-1050.

Yu, X.-X., Qiu, W.-L., Yang, L., Li, L.-C., Zhang, Y.-W., and Xu, C.-R. (2018). Dynamics of chromatin marks and the role of JMJD3 during pancreatic endocrine cell fate commitment. Development 145.

Zeng, C., Mulas, F., Sui, Y., Guan, T., Miller, N., Tan, Y., Liu, F., Jin, W., Carrano, A.C., Huising, M.O., et al. (2017). Pseudotemporal Ordering of Single Cells Reveals Metabolic Control of Postnatal $\beta$ Cell Proliferation. Cell Metab. 25, 1160-1175.e11.

Zhu, A., Ibrahim, J.G., and Love, M.I. (2019). Heavy-tailed prior distributions for sequence count data: removing the noise and preserving large differences. Bioinformatics 35, 20842092. 
bioRxiv preprint doi: https://doi.org/10.1101/2020.11.29.402990; this version posted November 30, 2020. The copyright holder for this preprint (which was not certified by peer review) is the author/funder, who has granted bioRxiv a license to display the preprint in perpetuity. It is made

A

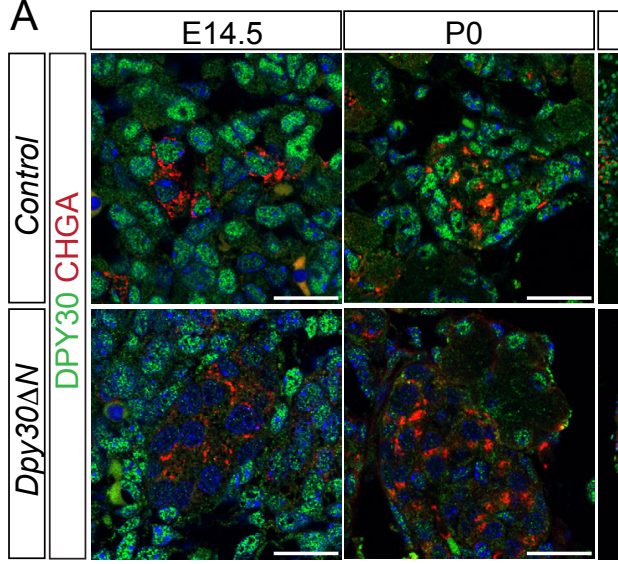

available under aCC-BY-NC-ND 4.0 International license.

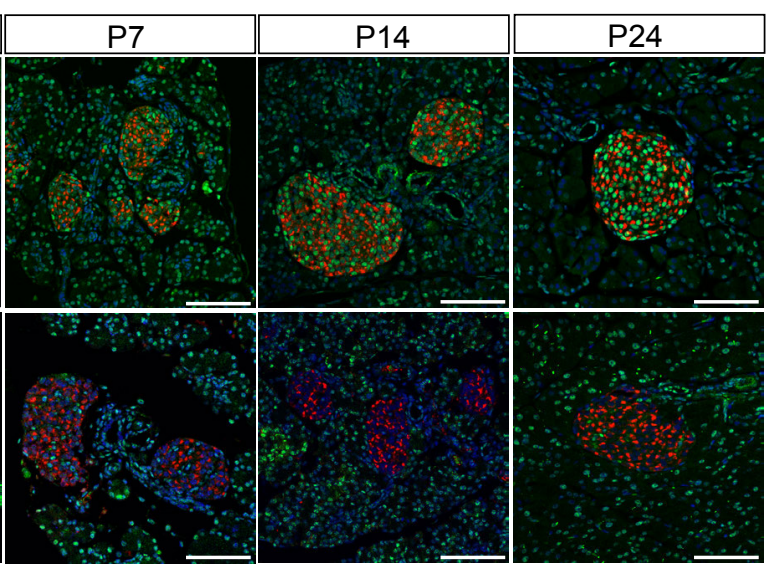

C
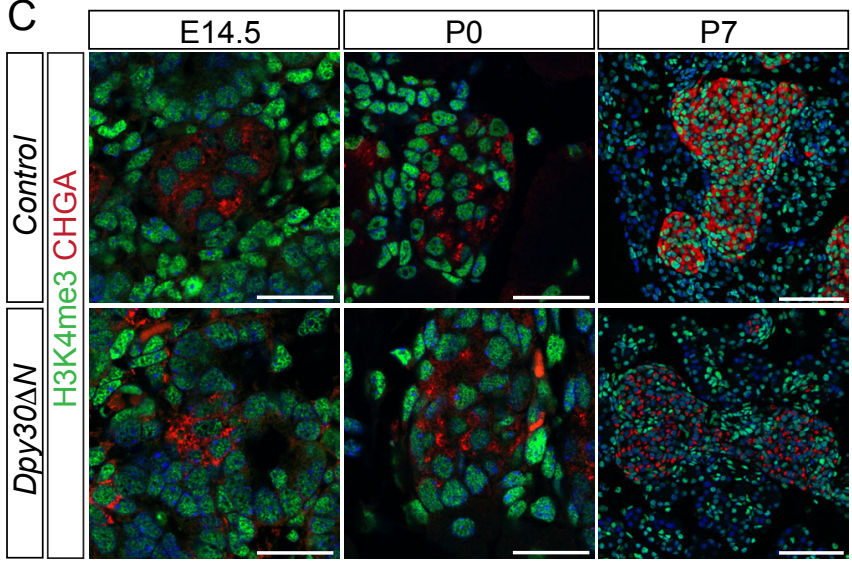

$\mathrm{F}$

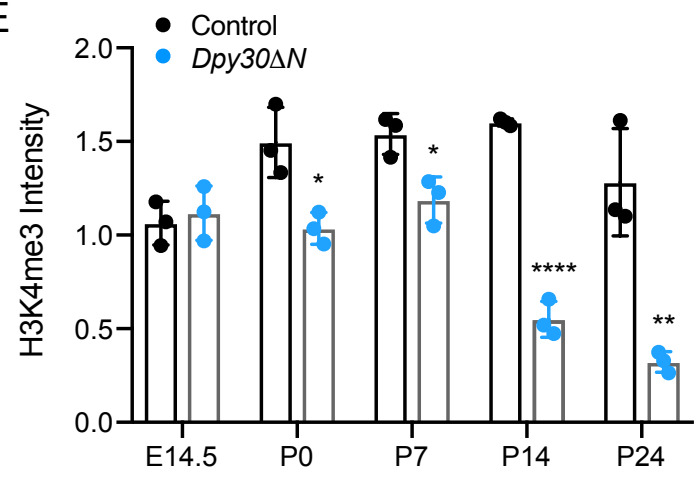

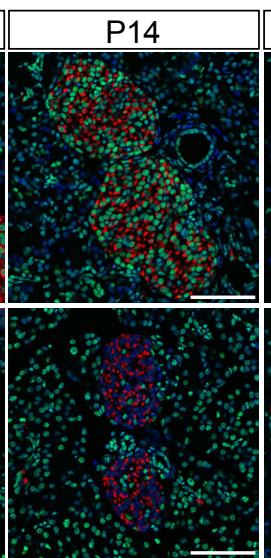

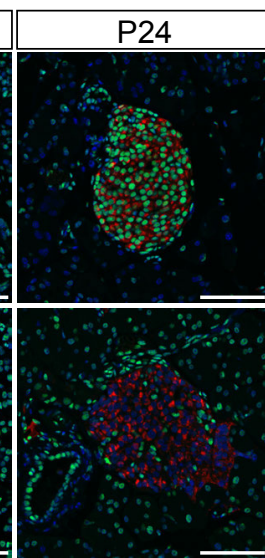

B

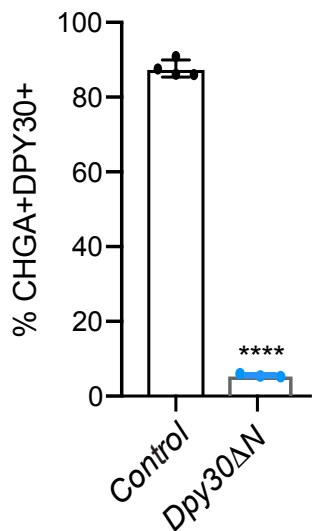

D
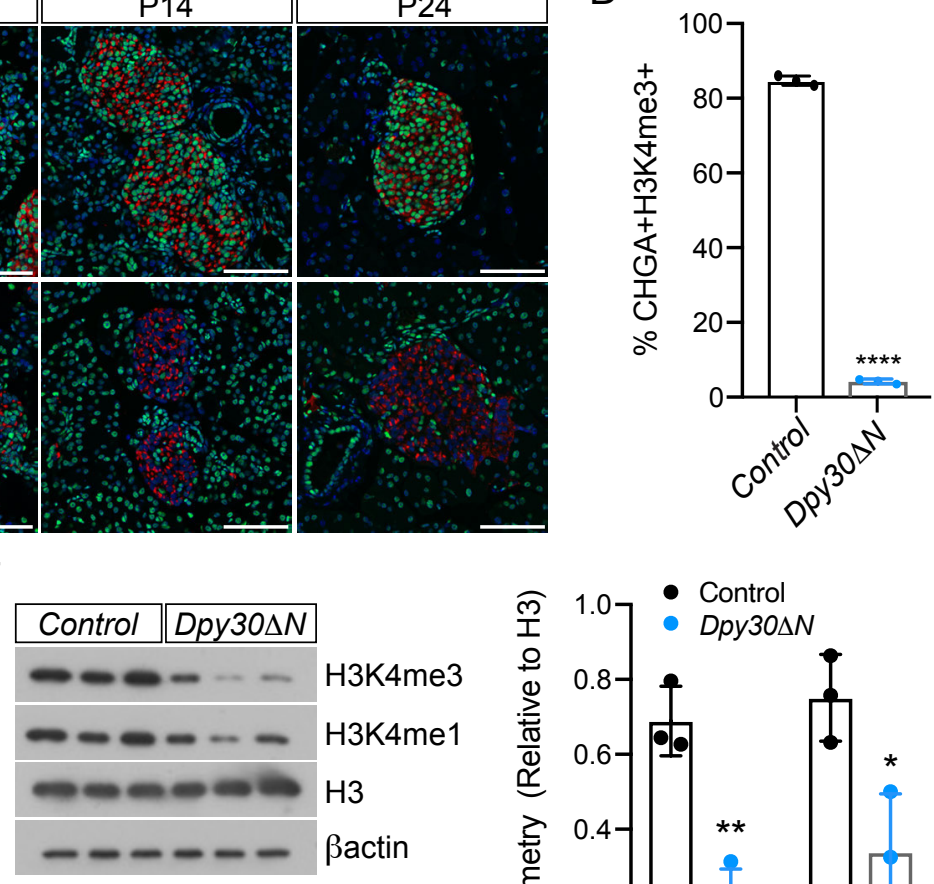

- Control

- $D p y 30 \Delta N$

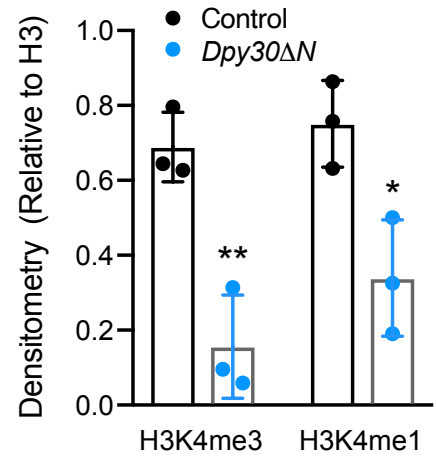

Figure 1: Dpy30 deletion in pancreas endocrine progenitor cells leads to progressive loss of $\mathrm{H} 3 \mathrm{~K} 4$ methylation in $D$ py $30 \Delta N$ islets.

(A) Staining of DPY30, chromogranin A (CHGA) and nuclei (blue) in control and Dpy30 $\Delta N$ pancreas from E14.5 to P24. (B) The percentage of CHGA+DPY30+ cells in P24 control and Dpy30 $\Delta N$ pancreas. (C) Staining of $\mathrm{H} 3 \mathrm{~K} 4 \mathrm{me}$, CHGA and nuclei (blue) in control and Dpy30 $\mathrm{N}$ pancreas from E14.5 to P24. (D) The percentage of CHGA+/H3K4me3+ cells in $\mathrm{P} 24$ control and Dpy30 $\Delta$ N pancreas. (E) The median H3K4me3 intensity in control and Dpy30 $\mathrm{N}$ CHGA+ cells relative to surrounding non-CHGA+ cell H3K4me3 intensity from E14.5 to P24. (F) Western blot and densitometry for $\mathrm{H} 3 \mathrm{~K} 4 \mathrm{me} 3$ and $\mathrm{H} 3 \mathrm{~K} 4 \mathrm{me} 1$ relative to histone $\mathrm{H} 3$ from $\mathrm{P} 24$ control and Dpy $30 \Delta N$ islets. Data is presented as mean $\pm \mathrm{SD} ; \mathrm{n}>3$; Dpy $30 \Delta N$ vs. control; unpaired, two-tailed Student's t-test. Scale bar, $25 \mu \mathrm{m}$ (E14.5, P0) and $75 \mu \mathrm{m}$ (P7-P24). 

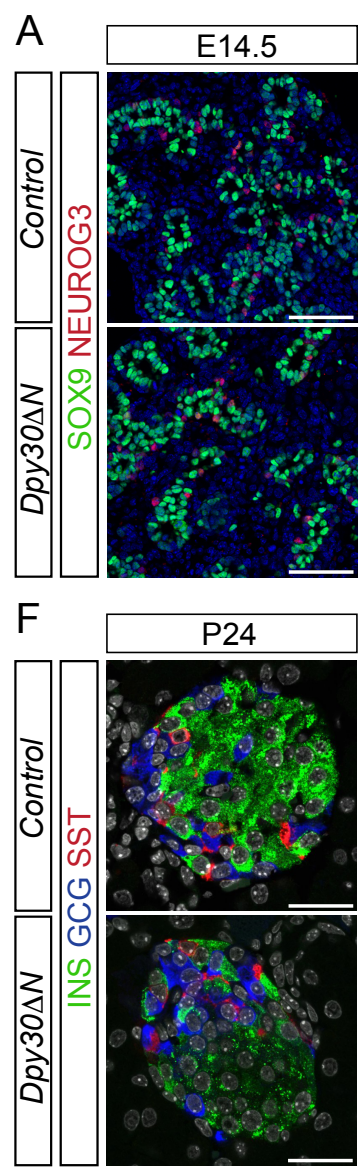

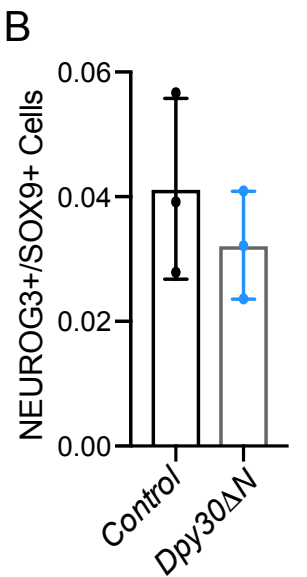

G

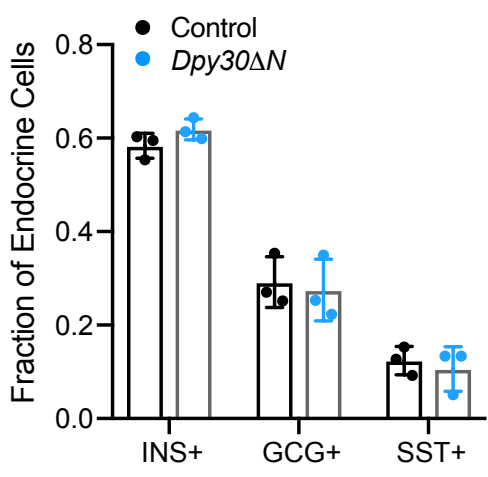

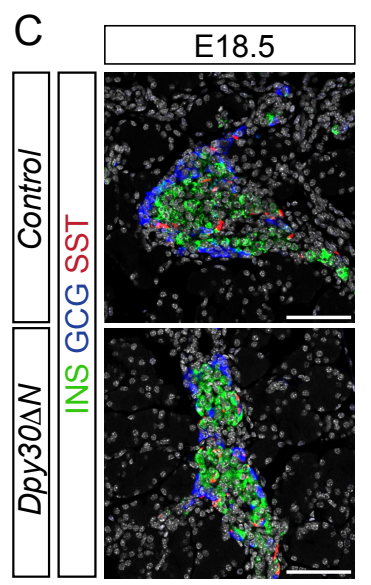
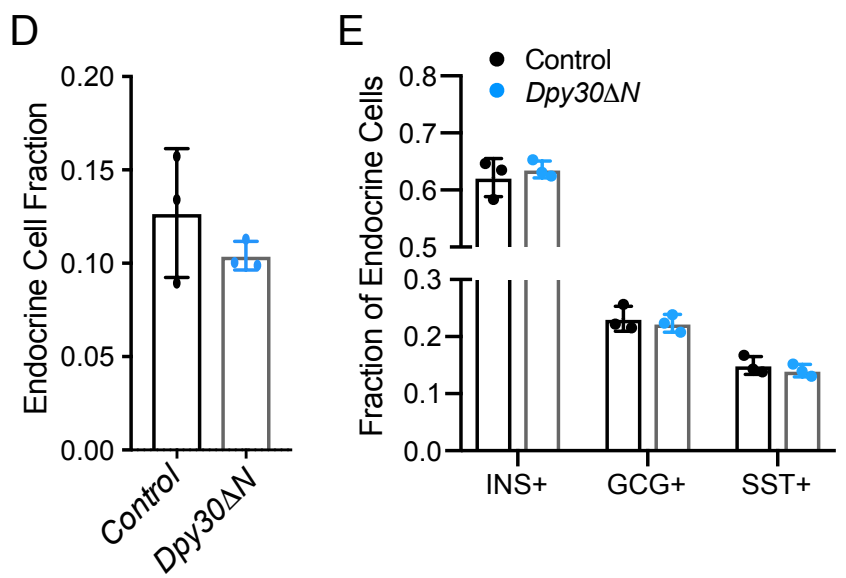

Figure 2: The proportion of endocrine cells is not altered in $D p y 30 \Delta \mathrm{N}$ mice.

(A) Staining for SOX9, NEUROG3 and nuclei (blue) in E14.5 control and Dpy30 $\Delta N$ pancreas. (B) The NEUROG3+/SOX9+ cell ratio in E14.5 control and Dpy30 $\mathrm{N}$ pancreas. (C) Co-staining for insulin (INS), glucagon (GCG), somatostatin (SST) and nuclei (grey) in E18.5 control and Dpy30 $N$ pancreas. (D) The fraction of endocrine cells (sum of INS+, GCG+ and SST+ cells) relative to pancreas cells in E18.5 control and Dpy30 $N$ pancreas. (E) The proportions of insulin $+\beta$-cells (INS+), glucagon+ $\alpha$-cells (GCG+) and somatostatin+ $\delta$-cells (SST+) relative to total endocrine cells in E18.5 control and Dpy30 $\Delta N$ pancreas. (F) Co-staining for insulin (INS), glucagon (GCG), somatostatin (SST) and nuclei (grey) in P24 control and Dpy $30 \Delta N$ pancreas. (G) The proportions of INS+, GCG+ and SST+ cells relative to total endocrine cells in P24 control and $D p y 30 \Delta N$ pancreas. (H) Quantification of CHGA+ area in P24 control and Dpy30 $\Delta N$ pancreas. Data are presented as mean $\pm \mathrm{SD} ; \mathrm{n}=3$; Dpy30 $\Delta N$ vs. control; unpaired, two-tailed Student's t-test. Scale bar, $75 \mu \mathrm{m}$. 
bioRxiv preprint doi: https://doi.org/10.1101/2020.11.29.402990; this version posted November 30, 2020. The copyright holder for this preprint (which was not certified by peer review) is the author/funder, who has granted bioRxiv a license to display the preprint in perpetuity. It is made available under aCC-BY-NC-ND 4.0 International license.
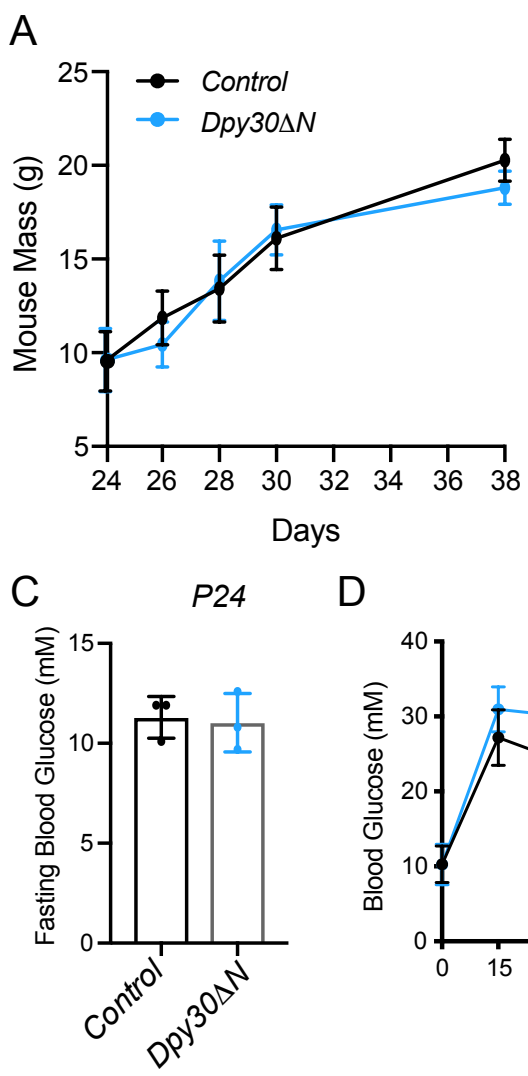

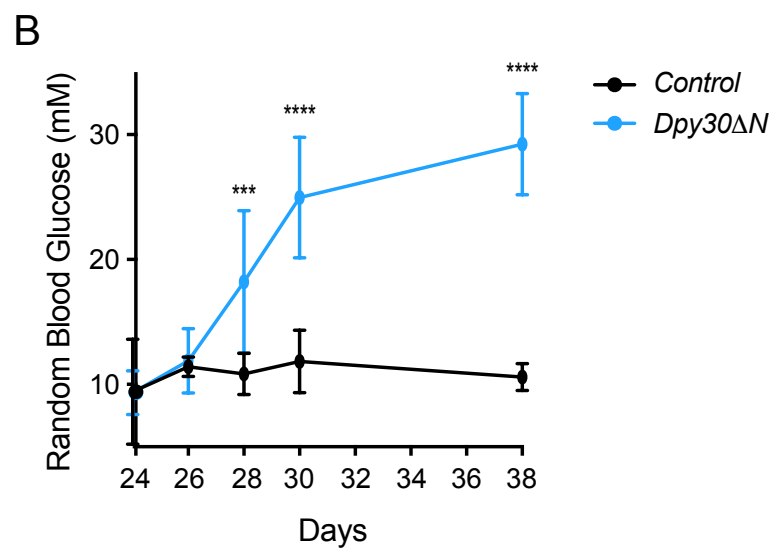

$P 24$

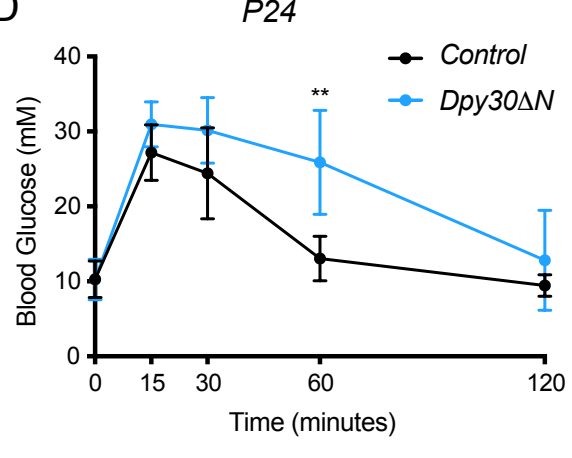

E

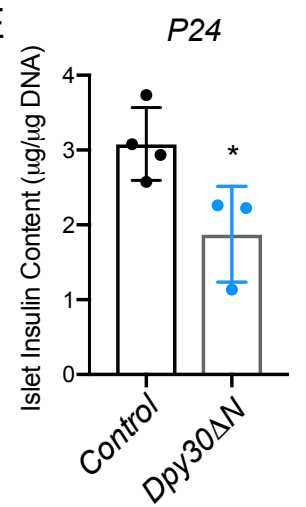

Figure 3: $D p y 30 \Delta N$ mice develop hyperglycemia and impaired glucose tolerance.

(A) Mouse body mass measurements between P24 and P38 in male control and Dpy30 $\Delta N$ animals. (B) Random blood glucose measurements from male Dpy30 $\Delta N$ and control mice between P24 and P38. (C) Blood glucose measurements after a 6 hour fast in P24 male control and Dpy30 $\Delta \mathrm{N}$ mice. (D) IPGTT of $2 \mathrm{~g}$ per kg body mass IP glucose in P24 male control and Dpy30 $\Delta \mathrm{N}$ mice following a 6 hour fast. (E) Islet insulin content relative to DNA from P24 male control and Dpy30 $\Delta N$ islets. Data are presented as mean \pm SD; $\mathrm{n}>3 ; D p y 30 \Delta N$ vs. control; multiple $t$ tests with Holm-Sidak correction for multiple comparisons (in A and B); unpaired, two-tailed Student's $t$ test (in $\mathrm{C}$ and $\mathrm{E}$ ); repeated measures two-way ANOVA with Sidak's multiple comparison post-hoc test (in D). Note that statistical testing was not performed at 15 and 30 minutes (in D) as measurements were above the detection limit (33.3 mM). 
bioRxiv preprint doi: https://doi.org/10.1101/2020.11.29.402990; this version posted November 30, 2020. The copyright holder for this preprint (which was not certified by peer review) is the author/funder, who has granted bioRxiv a license to display the preprint in perpetuity. It is made available under aCC-BY-NC-ND 4.0 International license.

A

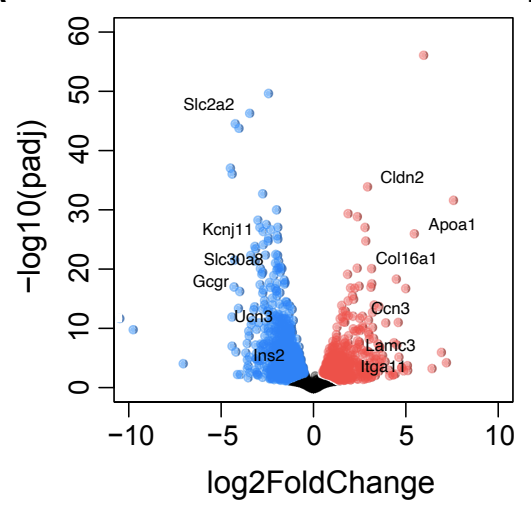

B

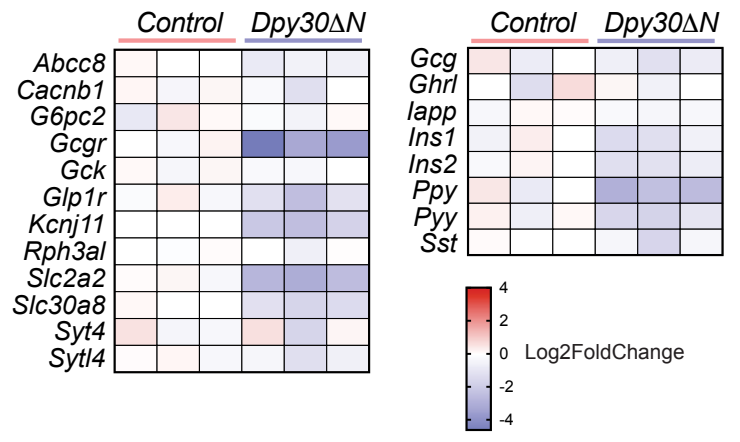

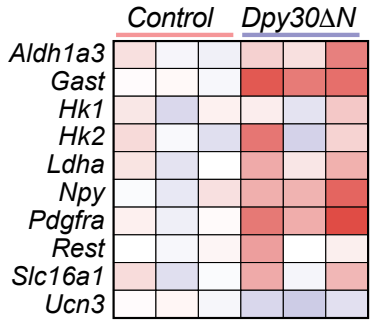

D

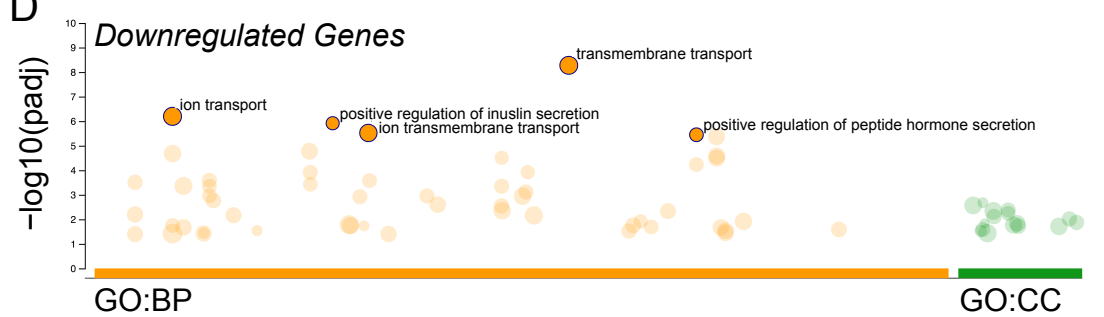

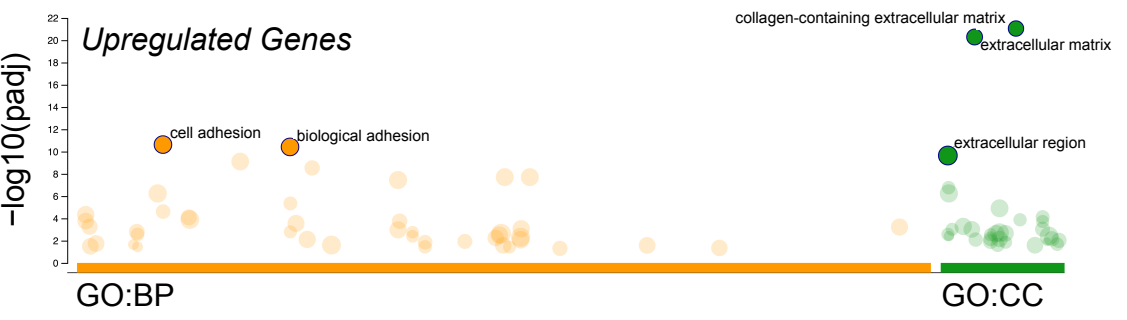

G
$E$

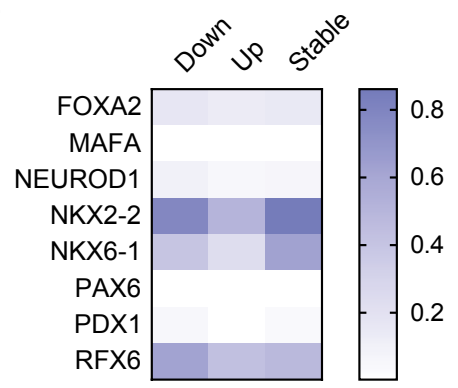

$\mathrm{F}$

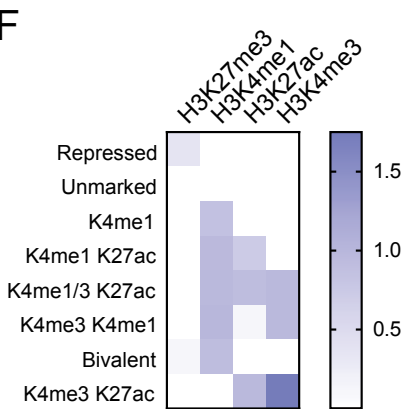

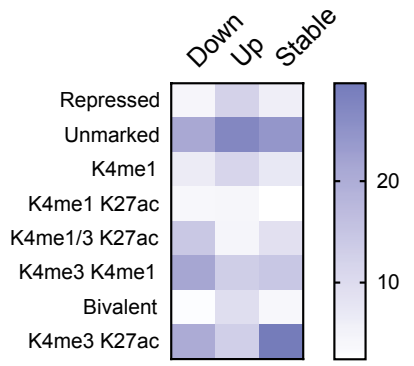

Figure 4: Islet maturity is compromised in $D p y 30 \Delta \mathrm{N}$ mice.

(A) Volcano plot of differentially expressed genes in P24 Dpy30 $N$ vs. control islets with log2 fold change plotted against the adjusted p-value (-log10). Downregulated genes are in blue, upregulated genes are in red and stable genes are in black. (B) Heatmaps of select gene expression (log2 fold change) comparing 3 biological replicates across P24 control and $D p y 30 \Delta N$ islets. (C) Overview of the glucose-stimulated insulin secretion pathway with affected genes in P24 Dpy30 $\Delta N$ islets represented by log2 fold change values. (D) g:Profiler GO term analysis of downregulated and upregulated genes from P24 control and Dpy30 $N$ islets represented as adjusted $p$-values (-log10). BP = biological process; CC = cellular component. (E) Heatmap of transcription factor occupancy from adult islet ChIP-seq data at downregulated, upregulated and stable genes in P24 Dpy30 $\mathrm{N}$ vs. control islets. (F) Histone modification enrichment plot of adult islet ChIP-seq data indicating repressed (H3K27me3), unmarked, poised (H3K4me1/3), active ( $\mathrm{H} 3 \mathrm{~K} 4 \mathrm{me} 1 / 3$ and $\mathrm{H} 3 \mathrm{~K} 27 \mathrm{ac})$ and bivalent (H3K4me1 and H3K27me3) chromatin states. (G) Heatmap showing the fraction of downregulated, upregulated and stable genes in P24 Dpy30 $\mathbf{N}$ vs. control islets in each chromatin state identified in (F). 
bioRxiv preprint doi: https://doi.org/10.1101/2020.11.29.402990; this version posted November 30, 2020. The copyright holder for this preprint (which was not certified by peer review) is the author/funder, who has granted bioRxiv a license to display the preprint in perpetuity. It is made available under aCC-BY-NC-ND 4.0 International license.
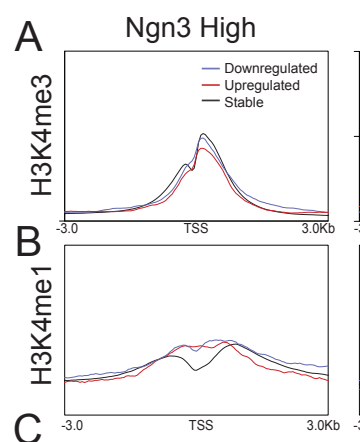

C
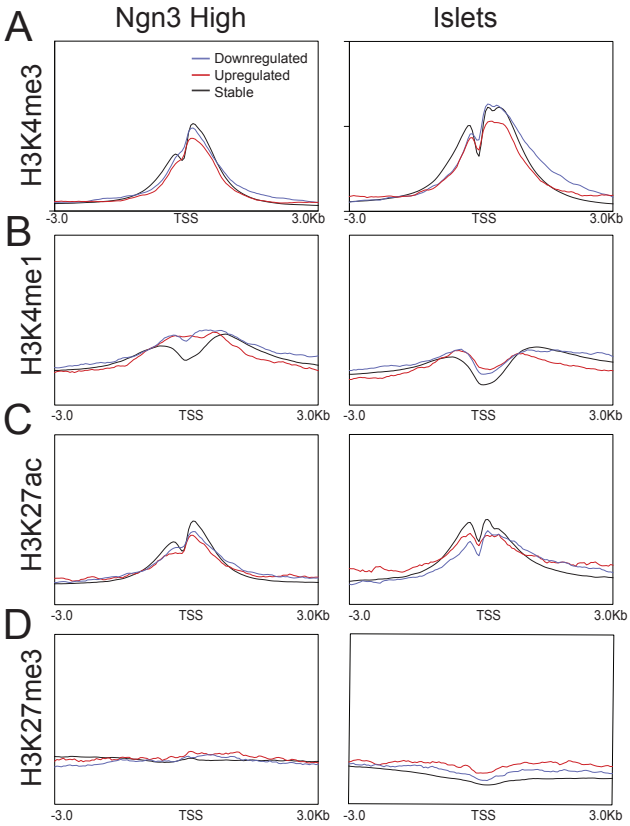

G
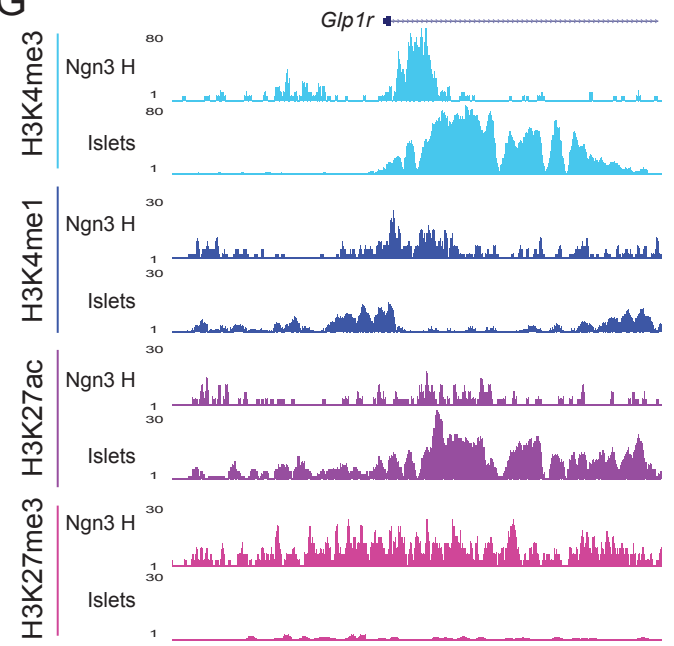

$\mathrm{E}$
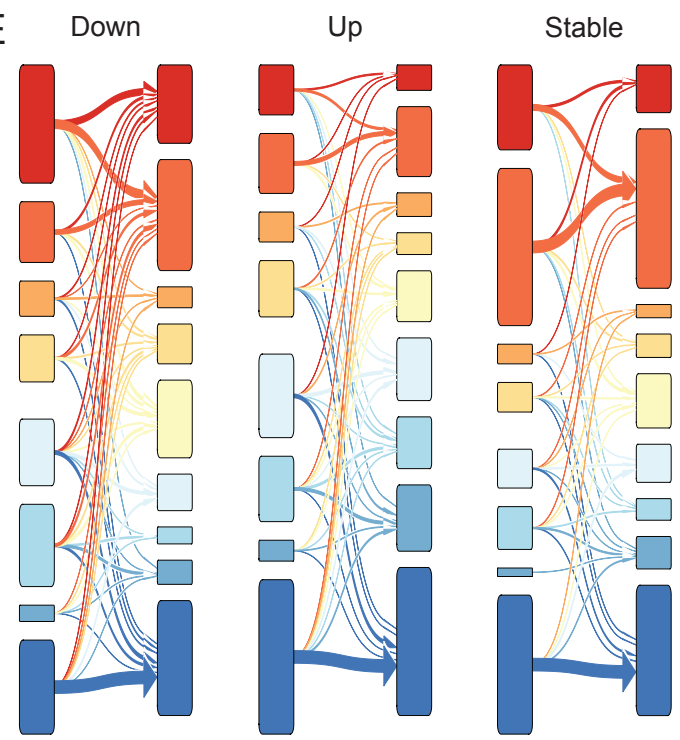

K27ac K4me3 K4me1

K27ac K4me3

K27ac K4me1

K4me3 K4me1

K4me3
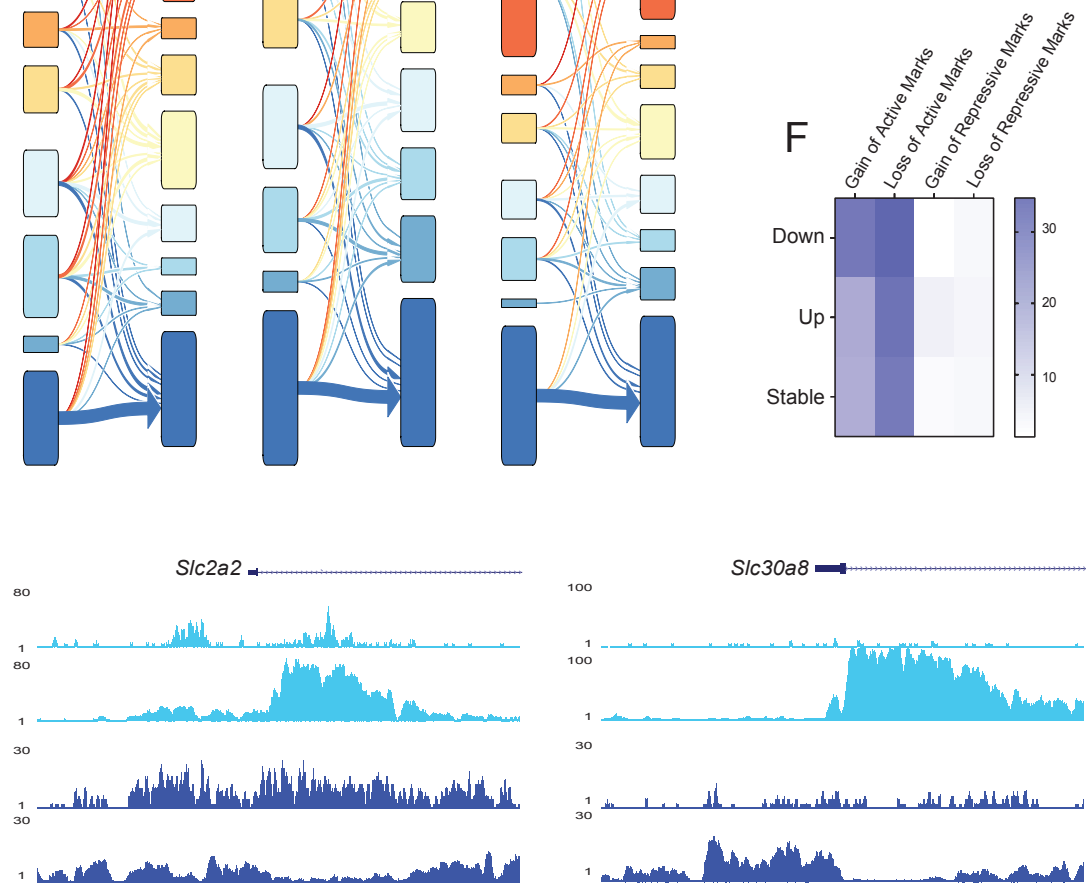

60

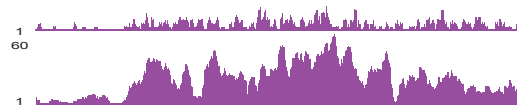

зо

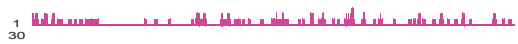

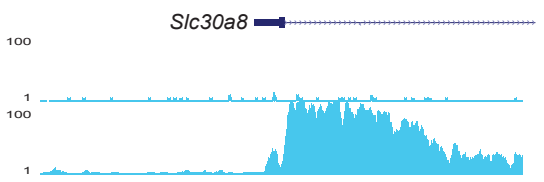
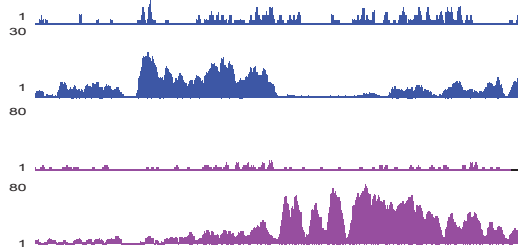

30

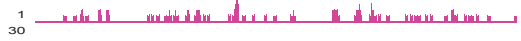

Figure 5: Genes downregulated in $D p y 30 \Delta N$ mice require activation during endocrine cell differentation.

(A-D) Comparison of histone modification profiles in E13.5 Neurog $3^{H 1}$ cells vs. adult islets around the TSS of downregulated, upregulated and stable genes in P24 Dpy30 $\mathrm{N}$ vs. control islets. Distributions for (A) H3K4me3, (B) H3K4me1, (C) H3K27ac and (D) H3K27me3 are shown $\pm 3.0 \mathrm{~kb}$ around the TSS. (E) Alluvial plot of chromatin state transitions for P24 islet Dpy30 $\Delta N$ downregulated, upregulated and stable genes from Neurog $3^{H /}$ cells to islets. (F) Heatmap summarizing the overall chromatin state transitions for P24 islet $D p y 30 \Delta N$ downregulated, upregulated and stable genes from Neurog $3^{H I}$ cells to islets. (G) Comparison of UCSC genome browser tracks at Glp1r, S/c2a2 and S/c30a8 for H3K4me3, $\mathrm{H} 3 \mathrm{~K} 4 \mathrm{me} 1, \mathrm{H} 3 \mathrm{~K} 27 \mathrm{ac}$ and H3K37me3 in Neurog $3^{\mathrm{HI}}$ cells and islets. 
A
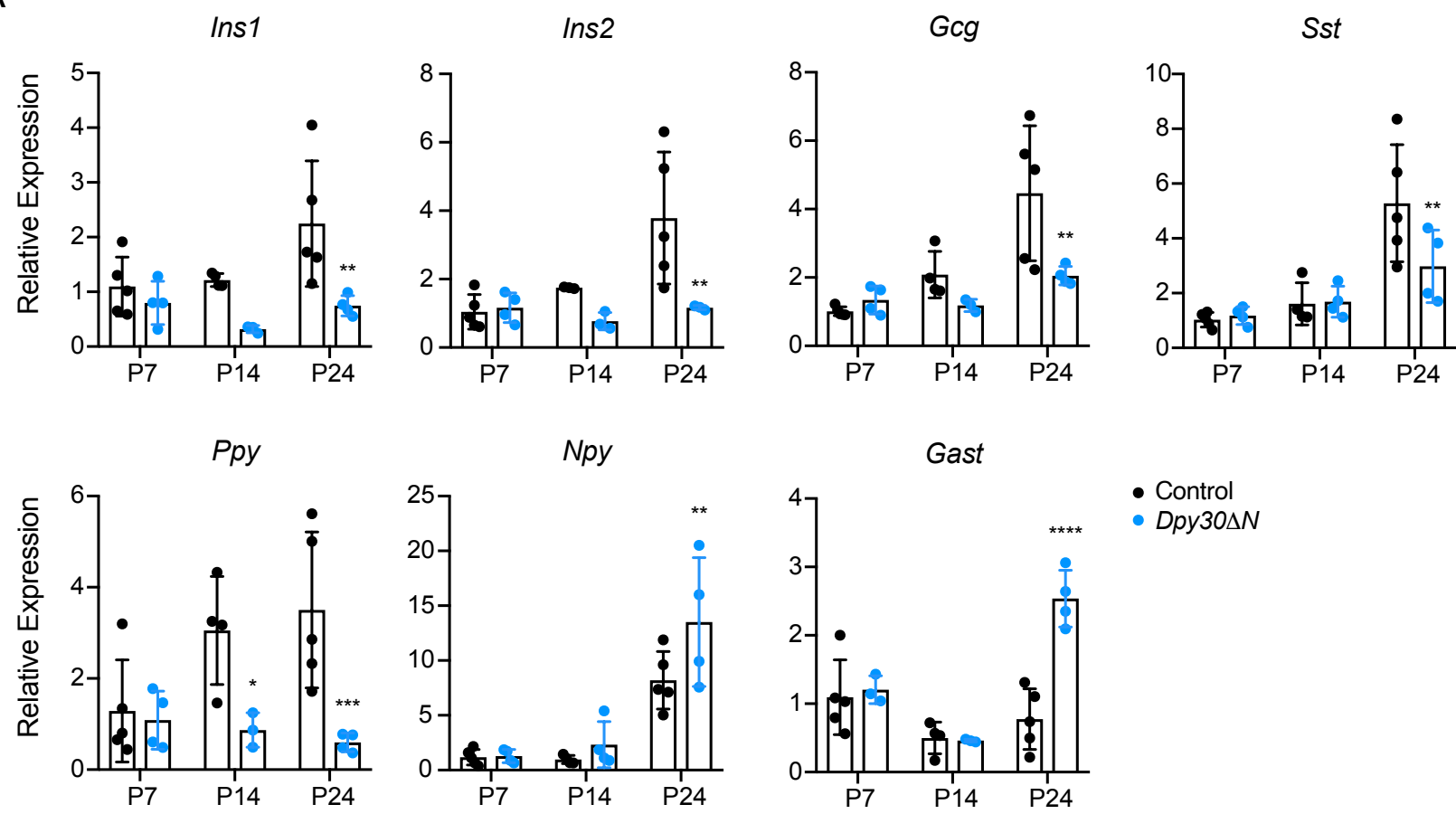

B

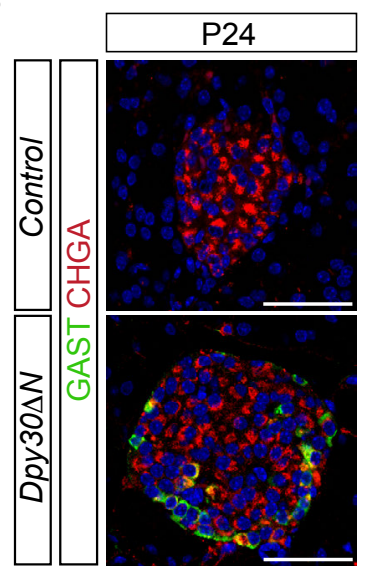

C

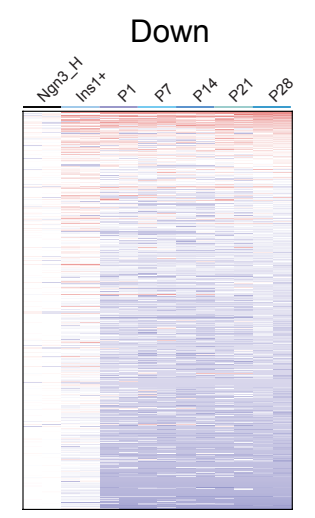

Up

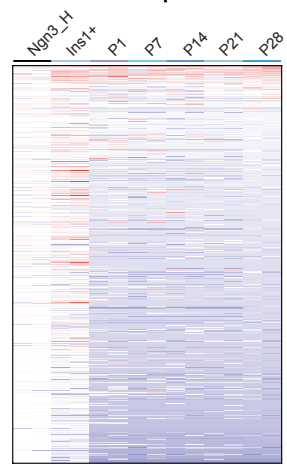

Stable

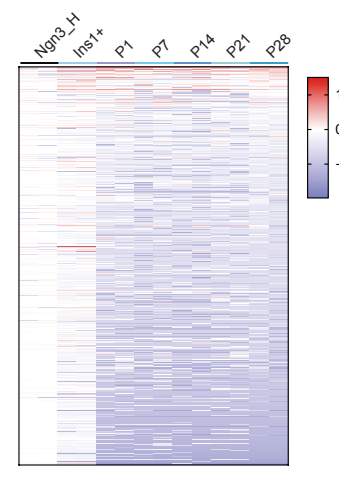

$\log _{2} \mathrm{FC}$ P28/Ngn3_H

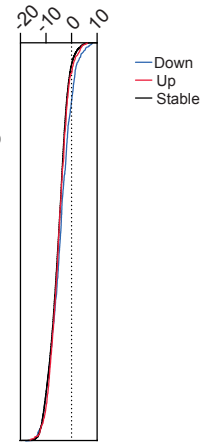

Figure 6: $D p y 30 \Delta N$ endocrine islet cells do not undergo functional maturation.

(A) Relative expression of Ins1, Ins2, Gcg, Sst, Ppy, Npy and Gast transcripts in P7, P14 and P24 control and Dpy30 $\Delta N$ islets $(n=4-5)$ as determined by qPCR. (B) Staining for gastrin (GAST), CHGA and nuclei (blue) in P24 control and Dpy30 $N$ pancreas. (C) Heatmaps of downregulated, upregulated and stable genes (identified in Figure 4) plotted as a developmental gene expression timeline. Data includes E13.5 5 Neurog $3^{H I}$ endocrine progenitors, E17.5 INS1+ $\beta$-cells and $\beta$-cells from P1, P7, P14, P21 and P28 islets. Gene expression (log2foldchange) from P28 islets was compared to E13.5 Neurog $3^{\text {Hl }}$ endocrine progenitors for the downregulated, upregulated and stable gene sets. Data are presented as mean \pm SD; Dpy $30 \Delta N$ vs. control; unpaired, two-tailed Student's t-test. Scale bar, $50 \mu \mathrm{m}$. 